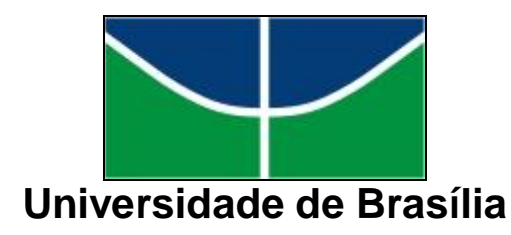

ROBERTA DA SILVA PAULA

KLOTHO SÉRICO COMO POTENCIAL BIOMARCADOR PARA EVENTOS CARDIOVASCULARES PRÉVIOS EM PACIENTES AMBULATORIAIS IDOSOS

BRASÍLIA-DF, 2016 


\author{
UNIVERSIDADE DE BRASÍLIA \\ FACULDADE DE CIÊNCIAS DA SAÚDE \\ PROGRAMA DE PÓS-GRADUAÇÃO EM CIÊNCIAS DA SAÚDE
}

ROBERTA DA SILVA PAULA

KLOTHO SÉRICO COMO POTENCIAL BIOMARCADOR PARA EVENTOS CARDIOVASCULARES PRÉVIOS EM PACIENTES AMBULATORIAIS IDOSOS

Tese apresentada como requisito parcial para obtenção do Título de Doutor em Ciências da Saúde pelo Programa de Pós-Graduação em Ciências da Saúde pela Universidade de Brasília.

Orientador: Prof. Dr. Otávio de Tolêdo Nóbrega

BRASÍLIA-DF 2016 


\section{KLOTHO SÉRICO COMO POTENCIAL BIOMARCADOR PARA EVENTOS CARDIOVASCULARES PRÉVIOS EM PACIENTES AMBULATORIAIS IDOSOS}

Tese apresentada como requisito parcial para obtenção do Título de Doutor em Ciências da Saúde pelo Programa de Pós-Graduação em Ciências da Saúde pela Universidade de Brasília.

Aprovada em

BANCA EXAMINADORA

Prof. Dr. Otávio de Toledo Nóbrega (presidente) UnB

Prof. Dr. Rivadávio Fernandes Batista de Amorim UnB

Prof. Dr. Luiz Sérgio Fernandes de Carvalho Unicamp

Prof ${ }^{\mathrm{a}}$. Dr ${ }^{\mathrm{a}}$. Sandra Fernandes Arruda UnB

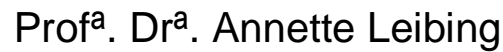

Université de Montréal/Canadá

Prof ${ }^{a}$. Dra ${ }^{\mathrm{a}}$. Eliza Carla Barroso Duarte (suplente)

UnB 
Dedico ao meu pai, que durante sua trajetória não mediu esforços para que eu tivesse a oportunidade de estudar, a minha família e em especial, ao meu esposo pelo incentivo e paciência. 


\section{AGRADECIMENTOS}

Agradeço a Deus pela vida, a minha família, ao meu esposo e todos aqueles

que convivo por ter entendido a minha ausência. Agradeço especialmente o meu orientador pela sua paciência e dedicação.

Sobretudo, agradeço aos profissionais do Projeto ProTeGer e todos àqueles que direta e indiretamente colaboraram para a conclusão deste trabalho. 


\section{RESUMO}

O número de óbitos por doenças vasculares é exorbitante em todo o mundo, e marcadores confiáveis ainda são necessários para esses eventos importantes. Diante disso, realizou-se um estudo transversal para investigar associação dos genótipos e dos níveis séricos de Klotho com fatores de riscos cardiovasculares clássicos e com história clínica de eventos cardiovasculares. Realizou-se análises clínica, antropométrica, bioquímica e nutricional com uma amostra de 168 idosos, complementada por genotipagem (rs9536314 e rs9527025) e detecção sérica (ELISA) de Klotho. Níveis de Klotho e seus haplótipos não se associaram com a maioria dos fatores de risco clássicos para eventos vasculares, tampouco com os marcadores, como a proteína C-reativa e a homocisteína. Observou-se associação positiva entre níveis circulantes de Klotho e ocorrência prévia de infarto do miocárdio por análises de correlação $(p=0,006)$ e de variância $(p<0,001)$. Propomos que níveis aumentados de Klotho sérico no pós-infarto do miocárdio podem consistir em mecanismo adaptativo contra hipertrofia miocárdica patológico, e pode representar um novo biomarcador para eventos em uma região específica.

Palavras-chave: biomarcadores; evento cardiovascular; desordem vascular; idoso; infarto; genotipagem; Klotho. 


\begin{abstract}
The number of deaths from vascular diseases is extremely high worldwide, and reliable markers for major events are still needed. This cross-sectional study investigated the association of Klotho haplotypes and of its serum levels with classic risk factors and clinical history of vascular events. Clinical, anthropometric, biochemical and nutritional assessments were conducted with 168 older adults, complemented by genotyping (rs9536314 and rs9527025) and detection of serum Klotho (ELISA). Klotho levels and haplotypes did not associate with most classic risk factors for vascular events, in parallel to marker as C-reactive protein and homocysteine assessed as well. A positive association was only found between Klotho levels and previous occurrence of myocardial infarction, by both correlational $(p=0.006)$ and variance analyses $(p<0.001)$. Increased post-myocardial infarction serum Klotho is suggestive of an adaptive mechanism against pathological hypertrophy, and may represent a new biomarker for events at a specific territory.
\end{abstract}

Keywords: biomarker; cardiovascular event; vascular disorder; elderly; infarction; genotyping; Klotho. 


\section{LISTA DE FIGURAS}

Figura 1- Comparação dos níveis circulantes de proteína C-reactiva (A), homocisteína (B) e Klotho $(C)$ entre os indivíduos que apresentavam infarto agudo do miocárdio (IAM) prévio ou não 


\section{LISTA DE TABELAS}

TABELA 1. Variáveis antropométricas, clínicas e metabólicas da amostra. .29

TABELA 2. Análises de correlação dos níveis séricos de proteína C-reativa, homocisteína e Klotho sobre os aspectos clínicos, bioquímicos e cuidados com a saúde dos 168 idosos avaliados. 31

TABELA 3. Análises de correlação dos níveis séricos de proteína C-reativa, homocisteína e Klotho em portadores e não-portadores de eventos vasculares desenvolvidos antes da admissão no estudo 32 


\section{LISTA DE SIGLAS}

ANP GDF-15: peptídeo natriurético atrial e fator-15 de diferenciação e crescimento AVE: acidente vascular encefálico

BNP NT-proBNP: peptídeo natriurético cerebral e seu fragmento $n$-terminal ativo CC: circunferência da cintura

CK-MB: creatinoquinase

CMI: Centro de Medicina do Idoso

CT: colesterol total

CT-1: cardiotrofina

DAC: doença arterial coronariana

DCVs: doenças cardiovasculares

DM: diabetes mellitus

DRC: doença renal crônica

ET-1: endotelina-1

FGF-23: fator de crescimento de fibroblastos-23

HAS: hipertensão arterial sistêmica

HbA1c: Hemoglobina glicada A1c

HDL: lipoproteína de alta densidade

HUB: Hospital Universitário de Brasília

HUCB: Hospital da Universidade Católica de Brasília

IAM: infarto agudo do miocárdio

IC: ingestão de carboidratos

IL: ingestão de lipídeos

IM: infartos do miocárdio

IP: ingestão de proteínas

LDL: lipoproteína de baixa densidade

MMSE: mini exame do estado mental

PAD: pressão arterial diastólica

PAS: pressão arterial sistólica

PC-R: proteína C-reativa

PCR: reação em cadeia da polimerase

PTH: paratormônio 
SNPs: polimorfismo de nucleotídeo único/single-nucleotide polymorphisms

ST2: proteína receptora de interleucina-1

TG: triglicerídeos

TRPC6: receptor de potencial transitório canônico 6/ transient receptor potential canonical 6

TSH: hormônio estimulante da tireoide

VET: valor energético total

VLDL: lipoproteína de muito baixa densidade 


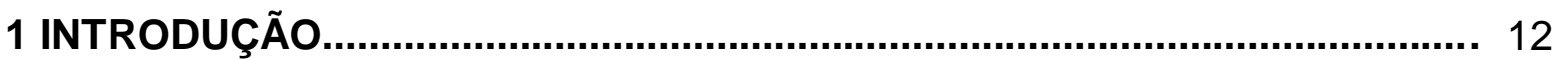

1.1 EPIDEMIOLOGIA DAS DOENÇAS CARDIOVASCULARES (DCVs)......... 12

1.1.1 Fatores de risco para desenvolvimento das DCVs ........................... 13

1.1.2 Transição nutricional............................................................... 14

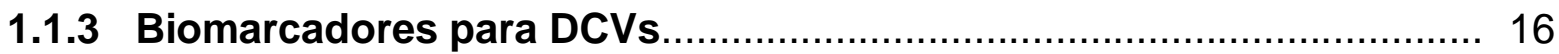

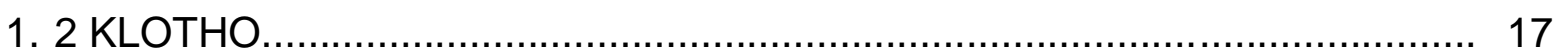

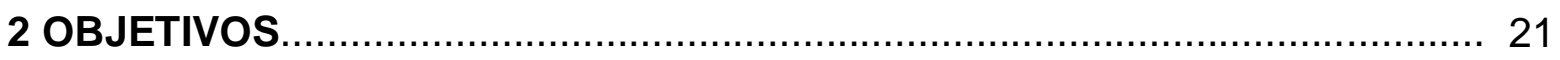

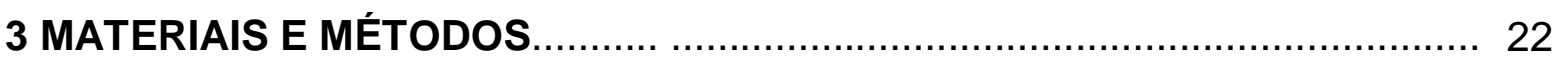

3.1 AMOSTRA E DESENHO DO ESTUDO................................................. 22

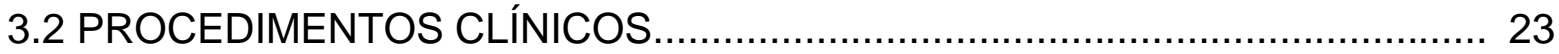

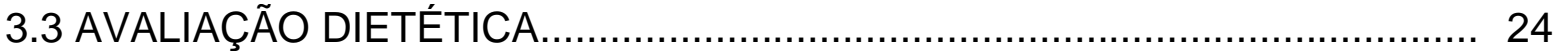

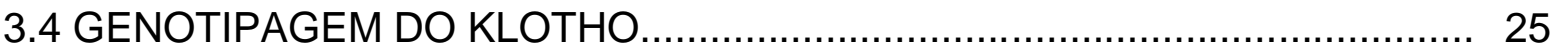

3.5 DETECÇÃO SÉRICA DA PROTEÍNA KLOTHO...................................... 26

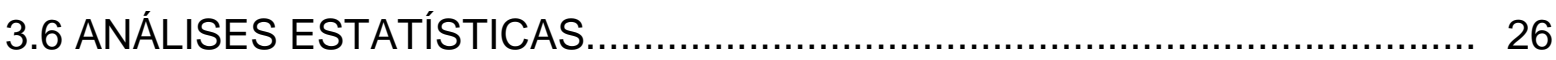

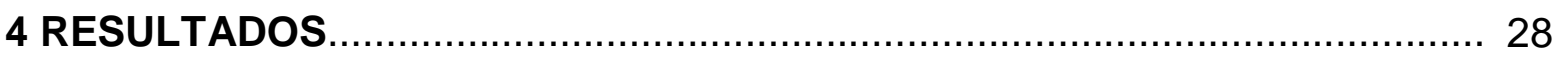

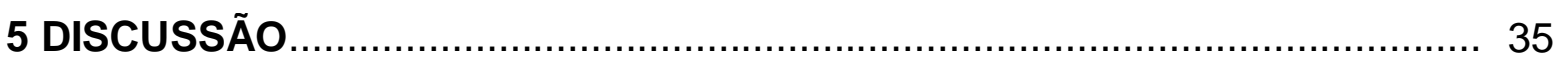

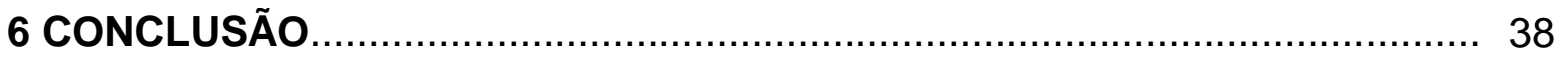

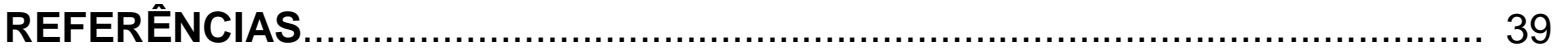

ANEXO A- PARECER DO COMITÉ DE ÉTICA E PESQUISA ......................... 45

ANEXO B- PROTOCOLO DE ATENDIMENTO CLÍNICO................................ 46

ANEXO C- PROTOCOLO DE ATENDIMENTO NUTRICIONAL........................ 47

ANEXO D- REGISTRO DE CONSUMO ALIMENTAR ESTIMADO .................. 49

ANEXO E- MINI EXAME DO ESTADO MENTAL ..................................... 51

ANEXO F- ARTIGO DA TESE ............................................................. 52 


\section{INTRODUÇÃO}

No cenário mundial, as doenças cardiovasculares foram responsáveis por 17,5 milhões de óbitos no ano de 2012, dos quais 7,4 milhões foram por doenças isquêmicas do coração e 6,7 milhões foram por acidente vascular encefálico (AVE). Ainda neste sentido, a doença arterial coronariana (DAC) é a causa mais frequente de morte no mundo, correspondendo a 12,8\% (mais de 7 milhões) do total de óbitos (1). Em 2010, a doença coronariana foi responsável por aproximadamente $1 \mathrm{em}$ cada 6 mortes nos Estados Unidos, totalizando 379.550 óbitos, enquanto na Europa, 1 a cada 6 homens e a cada 7 mulheres morreu por infarto do miocárdio (2). Segundo o Ministério da Saúde, em 2009 as doenças cardiovasculares corresponderam a $20 \%$ dos óbitos dos brasileiros com idade superior a 30 anos (3).

\subsection{EPIDEMIOLOGIA DAS DOENÇAS CARDIOVASCULARES (DCVs)}

Devido ao envelhecimento populacional e à mudança do perfil etário da incidência das doenças, a prevenção primária da doença aterosclerótica ocorrerá em faixas etárias cada vez mais elevadas. Os esforços de prevenção e tratamento das DACs têm como base o reconhecimento e controle dos fatores de risco. No entanto, a avaliação de risco cardiovascular na população idosa carece de ferramentas apropriadas uma vez que nos grandes estudos de prevenção primária, esta população encontrava-se sub-representada (4).

A mortalidade por doença aterosclerótica tem apresentado diminuição em indivíduos com idade inferior a 60 anos, porém sem alteração entre indivíduos acima de 60 anos (5). A prática do uso de estatinas na prevenção primária entre idosos, por exemplo, tem sido apoiada em análises de subgrupos e em poucos estudos voltados para a população mais velha (6).

O processo aterosclerótico inicia-se na infância com a formação de estrias gordurosas precursoras de placas aterogênicas, e estas começam a surgir aos 3 anos na aorta e, na adolescência, passam a atingir as coronárias, progredindo pelas 
outras fases do ciclo da vida $(7,8)$. Além disso, estudo epidemiológico sobre perfil lipêmico demonstrou que crianças e adolescentes com colesterol sérico elevado têm fator preditivo do nível de colesterol na vida adulta (9).

\subsubsection{Fatores de risco para desenvolvimento das DCVs}

Sendo a aterosclerose um processo crônico, progressivo e sistêmico, caracterizado por resposta inflamatória que pode se iniciar na infância e se manifestar tardiamente, esta possui etiologia multicausal por envolver diferentes fatores de risco (genéticos e de estilo de vida) que atuam em conjunto, determinando sua ocorrência em mais de 50\% da população adulta mundial (10-13).

Neste contexto, a doença arterial coronariana (DAC) é caracterizada pelo estreitamento do lúmen das artérias (estenose) pelo acúmulo de placas ateromatosas, levando a uma redução do fluxo sanguíneo ao músculo cardíaco (14), e que apresenta como fatores de risco obesidade, diabetes mellitus, hipertensão, tabagismo, hipercolesterolemia, história familiar e fatores genéticos. Como possível decorrência da DAC, infartos do miocárdio (IMs) podem resultar em morte do tecido cardíaco por período prolongado, com seu diagnóstico marcado por elevação de indicadores séricos de necrose miocárdica (preferencialmente troponina) quando acompanhada por aspectos clínicos como sintomas sugestivos de isquemia, novas ondas $Q$ no eletrocardiograma, ou evidência por imagens de perda de miocárdio viável ou de contratilidade ventricular (15).

No tocante às doenças cerebrovasculares, 90\% resultam de lesões das artérias carótidas (16-18) que podem resultar em acidente vascular encefálico (AVE) por oclusão súbita ou uma ruptura da vasculatura cerebral, arterial ou venosa (19). Assim, essa lesão cerebral pode ser hemorrágica ou isquêmica, essa última, definida como uma disfunção neurológica aguda num território arterial (20). Na maioria das vezes, este dano pode resultar em um evento trombótico agudo que se manifesta por hemiplegia, afasia ou convulsões (21). 


\subsubsection{Transição nutricional}

O mundo todo tem passado por uma série de mudanças desde a década de 1950, entre as quais as mais perceptíveis talvez sejam os fenômenos da urbanização e da globalização. Essas modificações afetam a qualidade dos alimentos produzidos e industrializados. As escolhas pelos alimentos são menos condizentes com o novo estilo de vida, mais aceitas ao paladar e menos satisfatórias ao aporte de nutrientes necessários à saúde em relação ao padrão anterior (22). Brasil não difere das demais partes do mundo, pois tende a adotar novos hábitos, criados pela indústria alimentar e marcados pelo excesso de produtos industrializados, diminuindo desta forma o consumo de produtos regionais e a tradição cultural $(23,24)$.

Além da globalização, também é desde a década de 1950 que os estudiosos verificaram que o consumo de lipídeos aumenta o risco de desenvolvimento de doenças cardiovasculares, e que o consumo de lipídeos superior a 35\% das calorias ingeridas habitualmente está relacionada à maior incidência de aterosclerose (25, 26). A contribuição da dieta para as doenças cardiovasculares se deve não só à quantidade, mas também aos tipos de gordura alimentar, pois estes influenciam a concentração de lipídeos e lipoproteínas no plasma (27). No que se refere, aos tipos de lipídeos, tanto os ácidos graxos saturados quanto o colesterol alimentar apresentam associação direta com a lipemia, em especial a colesterolemia; entretanto, a ingestão isocalórica de ácidos graxos saturados por ácidos graxos polinsaturados reduzem o colesterol total $(\mathrm{CT})$ e a lipoproteína de baixa densidade (low density lipoprotein, LDL) (28).

Decorrente destas mudanças, hoje os brasileiros têm uma dieta mais rica em gorduras saturadas, sódio e carboidratos simples, e deficientes em ômega-3 e fibras, ou seja, uma alimentação ocidentalizada, e essas têm sido relacionadas a uma maior tendência pró-inflamatória, pró-oxidante e pró-trombótica $(29,30)$. Embora 0 excesso no consumo de lipídeos saturados aumente 0 risco às doenças inflamatórias, uma alimentação saudável pode prevenir e tratar fatores de risco ao desencadeamento do processo aterosclerótico (31). 
Estudo epidemiológico sugere que as dislipidemias continuam sendo fator de risco para doença coronariana em indivíduos idosos apesar de o risco relativo diminuir nas faixas etárias mais avançadas (> 80 anos) (32). Embora a contribuição das dislipidemias tenha sido extensivamente demonstrada em estudos observacionais e experimentais na patogênese da aterosclerose e da doença arterial coronariana, estas evidências se restringiam apenas a indivíduos de meia-idade, e isto impossibilitava um consenso sobre como tratar a dislipidemia em idosos (33). Contudo, cabe ressaltar que consensos emanados pelas sociedades profissionais, a exemplo da Sociedade Brasileira de Cardiologia (34), passaram na atualidade a nortear a conduta clínica no sentido de que as dislipidemias em idosos não sejam negligenciadas ou enquadradas como achado menor, incidental em um quadro clínico mais complexo. 


\subsubsection{Biomarcadores para DCVs}

A Biotecnologia, cada vez mais disponível, têm contribuído nas últimas três décadas para a rápida evolução das áreas de saúde e principalmente da medicina, com novos marcadores moleculares sendo identificados e facilitando o diagnóstico preciso e em muitas vezes precoce de várias doenças de etiologia genética ou infecciosa. Dentre estas, podemos citar as inúmeras doenças metabólicas, autoimunes, parasitológicas e virais (22).

Dentre os fatores clínicos que comumente são avaliados enquanto fatores sugestivos do desencadeamento de eventos vasculares estão os níveis circulantes de homocisteína e de proteína C-reativa (PC-R), além de aspectos metabólicos como frações de colesterol (LDL e lipoproteína de alta densidade (HDL, High Density Lipoproteins Cholesterol) e níveis de lipoproteínas, entre outras. Tanto homocisteína quanto PC-R tendem a apresentar-se em concentrações elevadas em indivíduos com risco aumentado para a ocorrência de eventos vasculares (35). Apesar de a PC-R predizer eventos de doença cardíaca coronariana independentemente de outros fatores de riscos (36-38), seus níveis podem estar transitoriamente aumentados por 2 ou 3 semanas em virtude de uma grande infecção, trauma ou evento isquêmico extra-cardíaco (39), o que pode comprometer uma avaliação clínica segura embasada nestes marcadores. Além disso, é necessário considerar que os níveis circulantes de homocisteína são inversamente modulados pela ingestão das vitaminas B6, B12 e folato (40-43). A insuficiência renal crônica também pode interferir no metabolismo desse biomarcador, levando a hiperhomocisteinemia (44). Assim, a baixa especificidade destas moléculas tem mostrado a necessidade por se agregar novos biomarcadores para estratificação de risco para distúrbios vasculares (45). Atualmente a Sociedade Brasileira de Cardiologia tem indicado para o diagnóstico específico de infarto agudo do miocárdio (IAM) na prática clínica a dosagem de troponinas, creatinoquinase (CK-MB) e mioglobina, entretanto essas são mais utilizadas para avaliação nas primeiras horas após 0 início dos sintomas (46). Além desses biomarcadores, outros são utilizados com menos frequencia e podem contribuir para avaliação da evolução do IAM ou até mesmo na remodelação cardíaca, como o peptídeo natriurético cerebral (BNP) e seu 
fragmento n-terminal inativo (NT-proBNP), o peptídeo natriurético atrial (ANP) e 0 fator-15 de diferenciação e crescimento (GDF-15). Já a dosagem da proteína receptora da interleucina 1 (ST2), da cardiotrofina (CT-1) e da endotelina-1 (ET-1) também podem ser utilizadas para predizer a mortalidade após o IAM (47).

Pesquisas para definição de biomarcadores tanto em contexto clínico quanto experimental prosseguem mundialmente em busca de candidato(s) menos volúvel(is) a interferências por comorbidades associadas ou estilo de vida. Certamente que tais fatores são de grande valia na elaboração da conduta clínica de prevenção e tratamento. No entanto, muitas manifestações moleculares envolvidas no desenvolvimento e evolução da DAC, do IM e dos AVEs ainda são desconhecidas, o que abre um campo para estudos que podem auxiliar na identificação de novos fatores de risco.

\section{$1.2 \mathrm{KLOTHO}$}

A descoberta do gene Klotho ocorreu após um grupo de pesquisadores observar depois de quatro semanas de vida que um rato apresentava diversas manifestações próprias do envelhecimento precoce, como aterosclerose, calcificação vascular, alterações do metabolismo do cálcio e fósforo, osteoporose, atrofia cutânea e muscular, enfisema e diminuição da sobrevida (48). O fenótipo apresentado neste rato se deve à uma diminuição acentuada na expressão do gene Klotho, e a denominação desse gene se deve à deusa grega que estende o fio da vida (49). Estudos revelaram que a superexpressão do gene Klotho em modelo animal eleva em 20 a $30 \%$ a extensão total de vida de cobaias (50).

O gene Klotho está mapeado no braço longo do cromossomo 13 (13q12), contém 5 éxons e 4 introns, mede mais de $50 \mathrm{~Kb}$ e sua transcrição tem um tamanho de 5,2 Kb. Através de splicing alternativo obtem duas transcrições, uma que codifica uma proteína transmembranar de 1012 aminoácidos e uma outra proteína secretora de 549 aminoácidos $(49,51)$. Klotho humano apresenta 86\% dos aminoácidos idênticos às proteínas dos ratos, entretanto nos ratos predominam a codificação da 
forma transmembranar, enquanto nos seres humanos predominam a proteína de forma solúvel $(49,51)$.

O gene Klotho pode se exibir em diferentes formas alélicas por apresentar três pontos polimórficos notórios em sua região codificadora, sendo uma silenciosa e duas com troca de sentido (missense), onde estes últimos são causadores das trocas F352V (T->G, rs9536314) e C370S (G->C, rs9527025) na tradução da proteína. Ocorre completo desequilíbrio de ligação entre esses dois polimorfismos de base única (single-nucleotide polymorphisms, SNPs), de modo a conformarem os haplótipos FC e VS. Desta forma, a determinação de um destes SNPs é suficientemente informativa do outro, suscitando que se investigue tão somente a ocorrência dos homozigotos F/F (TT) e V/V (GG) ou do heterozigoto $F / V$ (TG) em estudos de associação genética com fenótipos específicos $(52,53)$.

A expressão do referido gene encontra-se principalmente no rim (especialmente ao nível das células do túbulo distal (51), local onde interage $\operatorname{com} \beta$ Klotho e o FGF-23) desempenhando um papel fundamental na homeostase de fosfato de cálcio $(48,54,55)$. Também pode ser encontrado em níveis mais baixos nas células ependimais do plexo cérebro coróide, pituitárias, das glândulas paratireóides, dos músculos esqueléticos, da placenta, da bexiga, do cólon, do ouvido interno, pâncreas, testículos e ovários $(51,55)$.

Quanto às funções de Klotho, foram realizados testes em camundongos selvagens e transgênicos, nos quais observou-se que camundongos $\mathrm{KL}^{-/}$com doença renal crônica (DRC) apresentavam calcificação precoce de tecidos moles em comparação com camudongos selvagens $\left(\mathrm{KL}^{+/+}\right)$igualmente portadores de DRC. Já camundongos com DRC que superexpressam Klotho (níveis preservados de Klotho) apresentam maior fosfatúria e, por isso, melhor função renal e menos calcificação de tecidos quando comparados com camundongos selvagens com DRC. Neste sentido, Klotho poderia ser considerado um biomarcador precoce das complicações clínicas da DRC (56).

Outra função de Klotho consiste em sua participação no aumento da atividade dos fatores de crescimento de fibroblastos (FGF), principalmente FGF-23. Este último é produzido especialmente pelo osso e lançado no plasma, cuja ação principal consiste em inibir a reabsorção renal de fósforo (ou seja, promover fosfatúria) e a expressão de 1a-hidroxilase (Cyp27b1), a qual promove a síntese de 
vitamina $D$. Os níveis plasmáticos de fosfato são regulados por vitamina $D$ e paratormônio (PTH), e as moléculas de Klotho e FGF-23 funcionam como reguladores negativos (eixo endócrino osso-rim-paratireóide) $(54,55,57)$. Neste sentido, estudo demonstrou que camundongos FGF-23-- $\mathrm{e} \mathrm{KL}^{-/}$apresentavam níveis séricos aumentados de 1,25 $(\mathrm{OH})_{2} \mathrm{D}_{3}$ e as mesmas anormalidades metabólicas (58). Embora a enzima 1 $\alpha$-hidroxilase seja essencial na síntese da vitamina $D$ ativa, sugere-se que estas duas moléculas citadas anteriormente regulem a expressão do gene 1 $\alpha$-hidroxilase. Acrescenta-se ainda que outras pesquisas em outros modelos de animais detectaram correlação do excesso de vitamina $D$ ativa e efeitos apoptóticos, levantando à hipótese de atuação como efeito cascata que a exposição de células a elevados níveis de vitamina $D$ pode apresentar efeitos citotóxicos em vários tecidos, resultando em atrofia dos mesmos $(59,60)$.

Além da relação com a atrofia de tecidos, os ésteres de vitamina $D$, o paratormônio, o fator de crescimento de fibroblastos- 23 , Klotho e inibidores da calcificação vascular estão envolvidos na evolução das placas de ateroma e consequente calcificação dos infiltrados (cálcio e fosfato). E esta calcificação caracteriza um forte e independente fator preditor de risco para eventos cardiovasculares, especialmente em pacientes com DRC (61).

A proteína Klotho pode representar um potencial marcador para eventos vasculares. Estudos em humanos têm indicado que a variante Klotho-VS está associada com a doença coronariana oculta. A despeito de apresentar frequencia populacional minoritária (16\%, em média), esta forma aparenta implicar menor atividade biológica de Klotho. Foi encontrada uma associação dessa variante funcional com menor sobrevida entre pessoas com história de eventos de AVE (62).

Ainda sobre a relação de Klotho com eventos cardiovasculares, sabe-se que a disfunção das células endoteliais tem sido sugerida como iniciadora do processo no desenvolvimento e progressão da aterosclerose. Para sustentar tal afirmação, identificaram que camundongos $\mathrm{KL}^{-/}$apresentam extenso e acelerado processo aterosclerótico (48). Ademais, eles exibem tanto a vasodilatação endotélioindependente (63) quanto angiogênese prejudicadas (64), sugerindo que a proteína Klotho possa proteger o sistema cardiovascular.

Mas a importância clínica de todas estas evidências supracitadas permanece indeterminada, o que mostra a necessidade do incentivo a pesquisas que visem uma 
melhor padronização dos testes, além de estudos com maior amostragem e diferentes critérios de seleção de pacientes. Esta abordagem viabilizaria a avaliação da associação de genótipos/fenótipos do gene Klotho e a predisposição à DAC, contribuindo para ações de prevenção, diagnóstico e estratificação de risco da doença. 


\section{OBJETIVOS}

\subsection{OBJETIVO GERAL}

- Investigar a associação dos genótipos e dos níveis séricos de Klotho com fatores de risco cardiovascular clássicos, assim como os eventos vasculares prévios em uma amostra de indivíduos idosos.

\subsection{OBJETIVOS ESPECÍFICOS}

- Caracterizar o perfil clínico, metabólico e antropométrico de pacientes idosos ambulatoriais, e classificá-los como portadores ou não de algum evento vascular prévio com base na anamnese médica;

- Quantificar a ingestão de macronutrientes (lipídica, glicídica e protéica), assim como a ingestão calórica total de cada paciente;

- Determinar a freqüência dos genótipos produzidos pelos polimorfismos mais comuns de Klotho na população investigada;

- Dosar os níveis circulantes de Klotho de cada indivíduo, assim como de proteína C-reativa e de homocisteína;

- Investigar a associação dos polimorfismos de Klotho e de seus níveis séricos com fatores de risco vascular, e a ocorrência de eventos vasculares prévios em análises controladas para possíveis fatores de confusão. 


\section{MATERIAIS E MÉTODOS}

\subsection{AMOSTRA E DESENHO DO ESTUDO}

Este estudo realizou análises de corte transversal com dados obtidos de mulheres e homens idosos da comunidade das periferias urbanas do Distrito Federal, com 60 anos ou mais e que se submeteram a exames de saúde (médicos, nutricionais e / ou farmacológicas) para avaliar risco cardiovascular em uma coorte denominada Prognóstico e Terapêutica em Geriatria (ProTeGer), em Brasília. Para a presente análise, foram considerados critérios de inclusão possuir idade $\geq 60$ anos e ter procurado espontaneamente por atendimento. Figuraram como critérios de exclusão ser portador de doenças auto-imunes, infecções crônicas ou recorrentes, doenças neoplásicas, doença renal crônica (clearence de creatinina $<25$ $\mathrm{mL} / \mathrm{min} / 1.73 \mathrm{~m}^{2}$ ), ter usado medicamento por indicação anti-inflamatória nos 30 dias que antecederam os exames clínicos e bioquímicos e/ou apresentar comprometimento cognitivo (após aplicado teste mini exame do estado mental).

Este estudo foi realizado em conformidade com a Declaração de Helsinki e orientações sobre as boas práticas clínicas, sendo aprovado pelo Comitê de Ética em Pesquisa da Faculdade de Medicina da Universidade de Brasília (Ofício no 061/2011- ANEXO A). A participação foi voluntária e os indivíduos participantes assinaram o termo de consentimento livre e esclarecido. Os dados foram coletados no período compreendido entre agosto de 2011 a julho de 2014, durante os atendimentos no Serviço de Geriatria do Hospital da Universidade Católica de Brasília (HUCB) e no Centro de Medicina do Idoso (CMI) do Hospital Universitário de Brasília (HUB).

Nenhum dos participantes recebia orientação nutricional no momento em que os dados laboratoriais e clínicos foram obtidos. 


\subsection{PROCEDIMENTOS CLÍNICOS}

Cada indivíduo passou por um protocolo clínico (ANEXO B) que consistia em exames bioquímicos, antropométricos e clínicos para a admissão no estudo. $\mathrm{Na}$ avaliação médica, foi investigada a ocorrência prévia de eventos vasculares como AVE, IM e DAC (angina) a partir da história clínica relatada pelo paciente e/ou seu acompanhante bem como pelos resultados de exames laboratoriais e/ou de imagem fornecidos pelos indivíduos. A ocorrência de qualquer evento vascular foi baseado no relato e computado apenas quando declarado de forma independente em pelo menos duas consultas médicas. Todas as consultas pelos profissionais clínicos sobre eventos anteriores foram realizadas de forma cega para as informações já disponíveis sobre os registros. Para nossas análises, os sujeitos foram segregados conforme portadores ou não de eventos vasculares prévios.

Presença de comorbidades como hipertensão arterial sistêmica (HAS), dislipidemias e diabetes mellitus II, entre outras, foi registrada, assim como o uso continuado de medicamentos para o controle das mesmas. As intervenções farmacológicas foram aplicadas livremente por cada médico dentro das terapêuticas previstas pelas diretrizes brasileiras de cada condição crônica. E foram considerados praticantes de exercícios físicos indivíduos que praticam 30 minutos ou mais de qualquer exercício durante pelo menos quatro dias por semana (65), enquanto que $o$ hábito de fumar foi definido como consumo de mais de 100 cigarros ao longo da vida (66).

Para a medida da circunferência abdominal foi utilizado fita métrica não extensível e localizado o ponto médio entre a última costela e a crista ilíaca no momento da expiração do indivíduo (67).

Os exames bioquímicos incluiram a determinação de colesterol total (CT), $\mathrm{HDL}$, triglicerídeos (TG), glicemia, hemoglobina glicada, insulina, PC-R, hormônio estimulante da tireoide (TSH) e homocisteína. Amostras de sangue venoso foram coletadas em tubo com EDTA, após um período de jejum de 12h. Os testes de laboratório foram realizados na sequência de análises clínicas de rotina com os reagentes da Boehringer Mannheim (Alemanha) e foram processados num dispositivo de aparelho Autohumalyzer (Humana GMBH, Alemanha). Lipoproteína de 
muito baixa densidade (Very Low Density Lipoproteins Cholesterol, VLDL) foi determinada dividindo os níveis TG por 5, enquanto que a equação de Friedewald foi usada para produzir LDL, por subtração de ambos VLDL e HDL do CT. Os casos foram avaliados como positivos ou negativos para montar variáveis categóricas para distúrbios metabólicos. A categorização de lipídeos foi realizada de acordo com do NCEP ATP III (68), com cada voluntário identificado como um portador (ou não) da hiperlipidemia mista (CT $\geq 200 \mathrm{mg} / \mathrm{dl}$, LDL $\geq 130 \mathrm{mg} / \mathrm{dl}$ e / ou TG $\geq 150 \mathrm{mg} / \mathrm{dl}$ ). O uso atual de drogas antilipêmicas foi considerado na definição de hiperlipidemia. A diabetes mellitus // foi definida de acordo com os valores de referência estabelecidos pela Associação Americana de Diabetes (glicemia de jejum $\geq 126$ mg / dl) (69) ou o uso atual de medicamentos hipoglicemiantes orais ou insulina. Pressão arterial sistólica e diastólica foram medidas como recomendado pelas Diretrizes Brasileiras de Hipertensão Arterial VI (70). Pacientes com pressão arterial sistólica $\geq 140 \mathrm{mmHg}$ e/ou a pressão arterial diastólica $\geq 90 \mathrm{mmHg}$, foram classificados como hipertensos, bem como aqueles que tomam regularmente medicamentos anti-hipertensivos.

O índice HOMA é um cálculo fundamentado na dosagem da insulina e glicose, ambas em jejum, com base na razão do produto entre insulinemia de jejum $(\mathrm{mU} / \mathrm{L})$ e glicemia de jejum (mmol/L) por 22,5 (71).

\subsection{AVALIAÇÃO DIETÉTICA}

O presente estudo avaliou o consumo habitual de macronutrientes por mulheres e homens idosos. Para avaliar o consumo alimentar, foram realizados anamnese nutricional com frequencia alimentar (ANEXO C) e registro alimentar (ANEXO D) de três dias não consecutivos, incluindo um dia de fim de semana. Para preencher os formulários corretamente, cada paciente recebeu orientações sobre 0 número e tamanhos das porções pelas nutricionistas treinadas. No caso de dúvida quanto o preenchimento do registro alimentar, a equipe de nutricionistas forneceu assistência pessoal ou por telefone.

De sete a dez dias depois de serem entregues os registros, os formulários foram devolvidos pelos pacientes durante a consulta e checado o preenchimento 
para verificar a exatidão e completar informações não preenchidas. A análise de composição de nutrientes foram realizadas com o software Pro Diet, versão 5i (AS Sistemas, Brasil), ajustado para todos os bancos de dados disponíveis e complementada com dados da Tabela de composição química de alimentos brasileiros (72). Os indivíduos cujos registros indicaram o uso de suplementos alimentares contendo macronutrientes foram excluídos do estudo.

Após a inserção de dados alimentares no programa, a ingestão total em gramas (g) de carboidratos, proteínas e lipídeos foram calculados individualmente. As ingestões absolutas foram convertidas em calorias relativas a partir desses macronutrientes em relação ao total de calorias na dieta. A ingestão de calorias total e todas as avaliações de macronutrientes foram determinadas como a ingestão diária média com base nos registros alimentares de 3 dias.

Para aumentar a confiabilidade dos dados coletados, foi aplicada uma versão em português do Brasil do mini exame do estado mental (Mini-Mental State Examination, MMSE) (73) (ANEXO E) em cada paciente, sendo as faixas de exclusão definidas conforme nível de escolaridade: < 13 para indivíduos analfabetos, $<17$ para indivíduos que tiveram de 1 a 7 anos de educação formal, e $<25$ para indivíduos que tiveram 8 ou mais anos de educação formal (74).

\subsection{GENOTIPAGEM DO KLOTHO}

Dez mililitros de sangue foram coletados por meio de punção venosa em tubos contendo heparina, com plasma obtido por centrifugação refrigerada $(4 \stackrel{\circ}{\circ})$ de $5 \mathrm{~mL}$ a $1.000 \mathrm{~g}$ por $15 \mathrm{~min}$. O plasma foi aliquotado e imediatamente congelado a $20 \stackrel{\circ}{ } \mathrm{C}$ até a realização dos testes.

Extração do DNA partiu de $5 \mathrm{~mL}$ de sangue pelo método de salting out (44). A determinação dos haplótipos FC e VS do gene Klotho foi realizada conforme descrito por Arking e colaboradores (52), com modificações. Brevemente, ambos sítios polimorfismos F352V (T/G; rs9536314) e C370S (G/C; rs9527025) foram amplificados em um mesmo segmento de DNA pela reação em cadeia da polimerase (PCR) com os primers forward 5' aggctcatgccaaagtctgg 3' e reverso 5' 
gtttccatgatgaacttttgagg 3'. Condições de amplificação consistiram em hot start a $80^{\circ} \mathrm{C}$ por 1 min seguido desnaturação inicial a $94^{\circ} \mathrm{C}$ por 2 min e de 36 ciclos a $94{ }^{\circ} \mathrm{C}$ por $40 \mathrm{~s}$, anelamento a $60 \stackrel{\circ}{\mathrm{C}}$ por $45 \mathrm{~s}$ e extensão a $72{ }^{\circ} \mathrm{C}$ por $50 \mathrm{~s}$, finalizado a 72 oC por 5 min. A amplificação dos produtos de 505 pb foi confirmada por eletroforese em gel de agarose a $1,6 \%$. Sendo detectado esgotamento dos iniciadores por verificação visual em gel, a identificação dos pontos polimórficos foi realizada de forma direta por sequenciamento automatizado dos produtos de amplificação em um sistema de DNA Analyzer 3130 (Foster City, CA, EUA), usando reagentes e procedimentos de acordo com o fabricante (Applied Biosystems). As reações de sequenciamento foram realizadas utilizando tanto o iniciador direto quanto o reverso para o passo de PCR.

\subsection{DETECÇÃO SÉRICA DA PROTEÍNA KLOTHO}

A concentração da proteína Klotho sérica foi determinada pelo método de ELISA (Enzyme-linked Immunosorbent Assay) por meio do kit específico produzido pela empresa Uscn Life Science Inc., de acordo com as instruções do fabricante.

\subsection{ANÁLISES ESTATÍSTICAS}

Para lidar com o objetivo de avaliar a ocorrência e a força da associação dos níveis séricos de Klotho e de outros biomarcadores clássicos com eventos vasculares prévios, nossas análises estatísticas começaram com a obtenção de coeficientes de correlação dos biomarcadores séricos investigados com variáveis contínuas e categóricas antropométricas, clínicas e bioquímicas com potencial condundidor no modelo principal. Para isso, distribuição próxima à normal foi avaliada para todas as variáveis contínuas pelo teste de Kolmogorov-Smirnov. A associação entre as variáveis contínuas foi avaliada pelo teste de correlação de Pearson, enquanto que o envolvimento de pelo menos uma variável categórica no 
modelo foi avaliado usando teste de Spearman, com homens e mulheres representados por 1 ou 2 e ausência ou presença de uma característica representada por 0 ou 1, respectivamente. Para testar se os genótipos na amostra encontravam-se em equilíbrio de Hardy-Weinberg, utilizamos o teste em Excel, disponível pelo endereço http://www.tufts.edu/ mcourt01/Documents/Court\%20lab \%20-\%20HW\%20calculator.xls. Sempre que uma interação foi notada, a associação dos biomarcadores com os eventos vasculares foi testada por meio de análises de correlação parcial analisados usando o ajuste para a(s) variável(is) de confusão ou estado. Além disso, as concentrações de cada biomarcador foram testados entre os indivíduos que apresentaram ou não infarto agudo do miocárdio (IAM) antes do início do estudo utilizando o teste $t$ Student. Quando os resultados mostraram diferenças significativas, a magnitude de efeito (effect size; $d$ ) e seu respectivo intervalo de confiança (IC 95\%) foram apresentados. Finalmente, a análise de regressão linear múltipla foi realizada para avaliar em que medida as concentrações séricas dos biomarcadores explicava a variabilidade na ocorrência dos eventos vasculares.

Todas as análises foram realizadas com o programa Statistical Package for the Social Sciences (SPSS) para Windows (versão 17.0). Para este estudo, um valor de $p$ (bicaudais) foi considerado significativo usando o princípio de correção de Bonferroni para comparações múltiplas sempre de uma dada característica é testada em relação a múltiplas variáveis independentes $k(k=10$ testes $\therefore \alpha \leq 0,005)$. 


\section{RESULTADOS}

Após a avaliação clínico-laboratorial e dietética, e sendo verificados os critérios de inclusão e exclusão, a amostra elegível foi de 168 indivíduos idosos, com idade média de 73,1 anos. Para o polimorfismo F352V, 138 (82,1\%) dos indivíduos eram homozigóticos FF, enquanto que 27 (16,1\%) tinham o genótipo FV e $3(1,8 \%)$ tiveram o genótipo VV. As mesmas proporções foram encontradas para os genótipos CC, CS e SS, com forte correspondência entre os alelos F e C, bem como a presença de $\mathrm{V}$ e $\mathrm{S}$ em cada genótipo individual, o que é consistente com $\mathrm{o}$ desequilíbrio de ligação perfeito dos dois SNPs em nossa amostra. Este resultado é altamente consistente com a suposição preconizada por Arking e colaboradores, segundo os quais o trabalho de identificação da variação F352V pode ser utilizada como substituto para a determinação de todo o haplótipo para fins de estudos epidemiológicos (75).

A Tabela 1 apresenta resultados de uma análise inferencial sobre os resultados, onde se buscou verificar a associação dos haplótipos de Klotho com as principais variáveis clínico-laboratoriais determinadas na amostra. Em termos clínicos, a caracterização da amostra revelou se tratar de indivíduos com proporção relativamente baixa de eventos vasculares prévios, mas com prevalência importante de distúrbios metabólicos, compatível, portanto com um perfil elegível para prevenção primária. A análise realizada não mostrou associação dos grupos alélicos estudados com quaisquer das variáveis de base. Além disso, não houve diferenças na prevalência de DAC prévia, AVE e casos de IAM entre os diferentes grupos de haplótipos. 
TABELA 1- Variáveis antropométricas, clínicas e metabólicas da amostra.

\begin{tabular}{|c|c|c|c|c|}
\hline \multirow[b]{2}{*}{ Variáveis } & \multicolumn{3}{|c|}{ Grupos } & \multirow[b]{2}{*}{$p$} \\
\hline & $\begin{array}{c}\text { Todos } \\
(\mathrm{n}=168)\end{array}$ & $\begin{array}{c}\mathrm{FC} / \mathrm{FC} \\
(\mathrm{n}=138)\end{array}$ & $\begin{array}{l}\text { /VS } \\
(\mathrm{n}=30)\end{array}$ & \\
\hline Masculino, $\%$ & 39,9 & 37,7 & 50,0 & 0,212 \\
\hline Idade, anos & $73,1 \pm 9,0$ & $73,0 \pm 8,7$ & $73,7 \pm 10,1$ & 0,677 \\
\hline $\mathrm{CC}, \mathrm{cm}$ & $97,4 \pm 11,5$ & $98,0 \pm 11,8$ & $95,2 \pm 9,9$ & 0,204 \\
\hline Nível de glicose, mg. $\mathrm{dl}^{-1}$ & $103,2 \pm 27,7$ & $104,4 \pm 29,9$ & $98,2 \pm 13,2$ & 0,082 \\
\hline $\mathrm{HbA} 1 \mathrm{c}, \%$ & $5,9 \pm 1,0$ & $5,9 \pm 1,1$ & $5,7 \pm 0,6$ & 0,280 \\
\hline Insulina, mUI/mL & $9,3 \pm 10,0$ & $9,7 \pm 10,8$ & $7,3 \pm 4,9$ & 0,230 \\
\hline Índice HOMA & $2,6 \pm 3,8$ & $2,8 \pm 4,1$ & $1,8 \pm 1,2$ & 0,163 \\
\hline $\mathrm{DM} 2^{\S}, \%$ & 22,6 & 26,1 & 6,7 & 0,021 \\
\hline Colesterol total, mg. $\mathrm{dl}^{-1}$ & $193,4 \pm 39,9$ & $192,3 \pm 36,2$ & $198,8 \pm 50,1$ & 0,404 \\
\hline $\mathrm{LDL}, \mathrm{mg} \mathrm{dl}^{-1}$ & $115,3 \pm 33,7$ & $114,4 \pm 33,1$ & $119,6 \pm 37,0$ & 0,448 \\
\hline Triglicerídeos, mg. $\mathrm{dl}^{-1}$ & $141,2 \pm 64,7$ & $143,3 \pm 62,1$ & $131,6 \pm 75,8$ & 0,370 \\
\hline Hiperlipemia $^{\S}, \%$ & 51,8 & 50,7 & 56,7 & 0,438 \\
\hline HDL, mg. $\mathrm{dl}^{-1}$ & $48,1 \pm 10,9$ & $47,5 \pm 10,6$ & $50,8 \pm 12,2$ & 0,135 \\
\hline PAS, $\mathrm{mm} \mathrm{Hg}$ & $134,8 \pm 19,5$ & $134,8 \pm 19,5$ & $134,5 \pm 19,8$ & 0,927 \\
\hline $\mathrm{PAD}, \mathrm{mm} \mathrm{Hg}$ & $80,6 \pm 11,1$ & $80,6 \pm 11,1$ & $80,8 \pm 11,8$ & 0,918 \\
\hline $\mathrm{HAS}^{\S}, \%$ & 77,4 & 78,3 & 73,3 & 0,559 \\
\hline PC-R, mg. $\mathrm{dl}^{-1}$ & $3,5 \pm 5,6$ & $3,7 \pm 5,8$ & $2,6 \pm 4,3$ & 0,339 \\
\hline TSH, mIU. $1^{-1}$ & $2,5 \pm 2,2$ & $2,6 \pm 2,3$ & $2,2 \pm 1,6$ & 0,294 \\
\hline Homocisteína, $\mu$ mol..$^{-1}$ & $12,8 \pm 8,8$ & $12,5 \pm 8,7$ & $14,0 \pm 9,1$ & 0,413 \\
\hline AVE prévio ${ }^{\S}, \%$ & 9,5 & 10,9 & 3,3 & 0,202 \\
\hline IAM prévio ${ }^{\S}, \%$ & 4,2 & 4,3 & 3,3 & 0,801 \\
\hline DAC prévio ${ }^{\S}, \%$ & 1,8 & 2,2 & - & 0,415 \\
\hline Sedentarismo $^{\S}, \%$ & 60,7 & 61,6 & 56,7 & 0,616 \\
\hline Tabagismo $^{\S}, \%$ & 37,3 & 36,5 & 41,4 & 0,621 \\
\hline Klotho, ng. $\mathrm{ml}^{-1}$ & $1,2 \pm 0,6$ & $1,2 \pm 0,6$ & $1,2 \pm 0,8$ & 0,743 \\
\hline
\end{tabular}

Os dados são expressos como médias \pm desvio padrão para variáveis contínuas ou frequências relativas para variáveis categóricas. Os testes $T$ Student ou o qui-quadrado foram usados. $\mathrm{CC}=$ circunferência da cintura; HbA1c = Hemoglobina glicada A1c; Índice HOMA = modelo homeostático de avaliação; DM2 = diabetes mellitus tipo 2; VLDL = very low density lipoprotein; LDL = low density lipoprotein; HDL = high density lipoprotein; PAS = pressão arterial sistólica; $\mathrm{PAD}=$ pressão arterial diastólica; HAS = hipertensão arterial sistêmica; $\mathrm{PC}-\mathrm{R}=$ proteína C-reactiva; $\mathrm{TSH}$ = hormônio estimulante da tireoide; IAM = infarto agudo do miocárdio; DAC = doença arterial coronariana. Limiar de significância $p \leq 0,002$ de acordo com a convenção de Bonferroni. 
Já a possibilidade de associação das variáveis clínico-laboratoriais e dietéticas da amostra com os níveis circulantes de Klotho foi realizada mediante testes de correlação (Tabela 2) onde marcadores séricos tradicionais para eventos vasculares (proteína C-reativa e homocisteína) foram considerados em meio às análises. Neste contexto, níveis séricos de proteína C-reativa e de homocisteína mostraram-se significativamente influenciados pelo sexo, com o nível médio do primeiro elevado em $87 \%$ entre mulheres $[p=0,012 ; d=0,23(0,1 ; 0,4)]$, e do segundo, em $34 \%$ entre homens $[p=0,020 ; d=-0,25(-0,4 ;-0,1)]$. Ademais, indivíduos sedentários exibiram nível sérico médio de PC-R $75 \%$ superior $[p=0,044$; $d=0,23(0,1 ; 0,4)]$ ao exibido por idosos fisicamente ativos. Além destas associações, as nossas análises de correlação revelaram não haver nenhuma outra associação significativa entre esses três marcadores biológicos e de qualquer variável clínica, bioquímica e alimentar investigadas. Portanto, níveis de Klotho não parecem ser influenciados por aspectos demográficos, de estilo de vida ou comorbidades apresentadas por pacientes em contexto de atenção primária. A ingestão de macronutrientes não apresentou correlação significativa com qualquer dos marcadores séricos considerados. 
TABELA 2- Análises de correlação dos níveis séricos de proteína C-reativa, homocisteína e Klotho sobre os aspectos clínicos, bioquímicos e cuidados com a saúde dos 168 idosos avaliados.

\begin{tabular}{|c|c|c|c|c|c|c|}
\hline & Idade & $\mathrm{Sexo}^{\S}$ & PAS & PAD & $\mathrm{HAS}^{\S}$ & $\alpha \mathrm{HAS}^{\S}$ \\
\hline PC-R & 0,$09 ; 0,242$ & 0,$23 ; 0,002$ & $-0,07 ; 0,399$ & $-0,10 ; 0,195$ & 0,$09 ; 0,268$ & 0,$09 ; 0,238$ \\
\hline Homocisteína & 0,$18 ; 0,022$ & $-0,25 ; 0,001$ & $-0,10 ; 0,203$ & $-0,18 ; 0,022$ & 0,$05 ; 0,544$ & 0,$070 ; 0,373$ \\
\hline \multirow[t]{2}{*}{ Klotho } & 0,$11 ; 0,178$ & 0,$06 ; 0,424$ & $-0,18 ; 0,025$ & $-0,16 ; 0,041$ & $-0,06 ; 0,473$ & $-0,05 ; 0,538$ \\
\hline & $\mathrm{CC}$ & Sedentarismo ${ }^{\S}$ & $\mathrm{HbA1c}$ & Índice HOMA & $\mathrm{DM} 2^{\S}$ & $\alpha \mathrm{DM} 2^{\S}$ \\
\hline PC-R & 0,$08 ; 0,289$ & 0,$23 ; 0,002$ & $-0,07 ; 0,400$ & 0,$20 ; 0,010$ & 0,$05 ; 0,492$ & 0,$01 ; 0,873$ \\
\hline Homocisteína & 0,$02 ; 0,791$ & 0,$11 ; 0,165$ & $-0,02 ; 0,764$ & 0,$01 ; 0,933$ & 0,$09 ; 0,233$ & 0,$01 ; 0,884$ \\
\hline \multirow[t]{2}{*}{ Klotho } & $-0,05 ; 0,524$ & 0,$07 ; 0,375$ & $-0,07 ; 0,353$ & $-0,07 ; 0,404$ & $-0,01 ; 0,898$ & 0,$03 ; 0,660$ \\
\hline & CT & LDL & $\mathrm{TG}$ & Hiperlipemia & HDL & alipêmicos ${ }^{\S}$ \\
\hline PC-R & 0,$03 ; 0,722$ & $-0,06 ; 0,433$ & $-0,01 ; 0,887$ & 0,$03 ; 0,686$ & $-0,03 ; 0,687$ & $-0,01 ; 0,968$ \\
\hline Homocisteína & $-0,12 ; 0,119$ & $-0,06 ; 0,474$ & $-0,03 ; 0,672$ & $-0,06 ; 0,476$ & $-0,09 ; 0,233$ & 0,$06 ; 0,405$ \\
\hline \multirow[t]{2}{*}{ Klotho } & $-0,18 ; 0,021$ & $-0,10 ; 0,204$ & $-0,05 ; 0,537$ & $-0,01 ; 0,935$ & $-0,06 ; 0,444$ & $-0,02 ; 0,802$ \\
\hline & Etilista $^{\S}$ & Tabagista $^{\S}$ & IC & IL & IP & VET \\
\hline PC-R & 0,$12 ; 0,108$ & 0,$13 ; 0,098$ & $-0,05 ; 0,610$ & $-0,04 ; 0,697$ & 0,$18 ; 0,050$ & $-0,04 ; 0,673$ \\
\hline Homocisteína & 0,$17 ; 0,025$ & 0,$12 ; 0,134$ & $-0,13 ; 0,161$ & 0,$13 ; 0,179$ & 0,$07 ; 0,484$ & 0,$01 ; 0,924$ \\
\hline Klotho & 0,$02 ; 0,790$ & 0,$14 ; 0,086$ & 0,$10 ; 0,277$ & $-0,19 ; 0,045$ & 0,$12 ; 0,193$ & $-0,20 ; 0,031$ \\
\hline
\end{tabular}

Utilizou-se o teste de correlação de Pearson ou Spearman§. Para esta última, a presença ou ausência de uma característica foi representada por 1 ou 0 , respectivamente. Os dados são expressos em Índice de correlação e nível de significância $(r ; p) . \alpha=$ uso de drogas terapêuticas (ou medicamentos) para a doença; $\mathrm{CC}=$ circunferência da cintura; $\mathrm{PAS}=$ pressão arterial sistólica; $\mathrm{PAD}=$ pressão arterial diastólica; $\mathrm{CT}=$ colesterol total; $\mathrm{LDL}=$ low density lipoprotein; $\mathrm{TG}=$ triglicerídeos; $\mathrm{HDL}=$ high density lipoprotein; Índice HOMA = Modelo homeostático de avaliação; HbA1c = Hemoglobina glicada A1c; HAS = hipertensão arterial sistêmica; DM2 = diabetes mellitus tipo 2; IC = ingestão de carboidratos; IL = ingestão de lipídeos; IP = ingestão de proteínas; VET = valor energético total. Limiar de significância $p \leq 0,002$ de acordo com a convenção de Bonferroni. 
Em seguida, análises de correlação foram realizadas para investigar uma possível associação dos biomarcadores PC-R, homocisteína e Klotho com a ocorrência de eventos vasculares prévios (AVE, IAM ou DAC) ao início do estudo (Tabela 3). Estas análises foram controladas para os fatores de confundimento (sexo e sedentarismo) anteriormente associados com alguns biomarcadores, e a principal resultante consistiu em uma associação positiva entre os níveis circulantes de Klotho e a ocorrência prévia de infarto agudo do miocárdio. Ao se comparar os níveis séricos de PC-R, homocisteína e Klotho entre sujeitos acometidos ou não por infarto agudo do miocárdio prévio, observa-se que Klotho consistiu no único marcador a exibir níveis diferenciados [ $>72 \%$ entre IAM+; $p<0,001 ; d=1,6(0,9-2,6)$ ] conforme a história pregressa do paciente (Figura 1).

TABELA 3- Análises de correlação dos níveis séricos de proteína C-reativa, homocisteína e Klotho em portadores e não-portadores de eventos vasculares desenvolvidos antes da admissão no estudo.

\begin{tabular}{lccr}
\hline \multicolumn{3}{c}{ Eventos vasculares } \\
\hline & AVE & IAM & DAC \\
\hline PC-R $^{\dagger, t}$ & 0,$14 ; 0,066$ & 0,$04 ; 0,615$ & $-0,06 ; 0,465$ \\
homocisteína $^{\dagger}$ & 0,$12 ; 0,124$ & 0,$01 ; 0,902$ & 0,$01 ; 0,911$ \\
Klotho & 0,$07 ; 0,381$ & $\mathbf{0 , 2 2} ; \mathbf{0 , 0 0 6}$ & $-0,13 ; 0,100$ \\
\hline
\end{tabular}

Os testes de Spearman ou correlação parcial (para ajustes) foram utilizados, ajustados para $\uparrow$ sexo e / ou atividade física $\$$ quando apropriado. A presença ou ausência de uma característica foi representada por 1 ou 0 , respectivamente. Os dados são expressos em índice de correlação e nível de significância $(r ; p) . \mathrm{IAM}=$ infarto agudo do miocárdio; DAC = doença arterial coronariana. Limiar de significância $p \leq 0,016$ de acordo com a convenção de Bonferroni. 

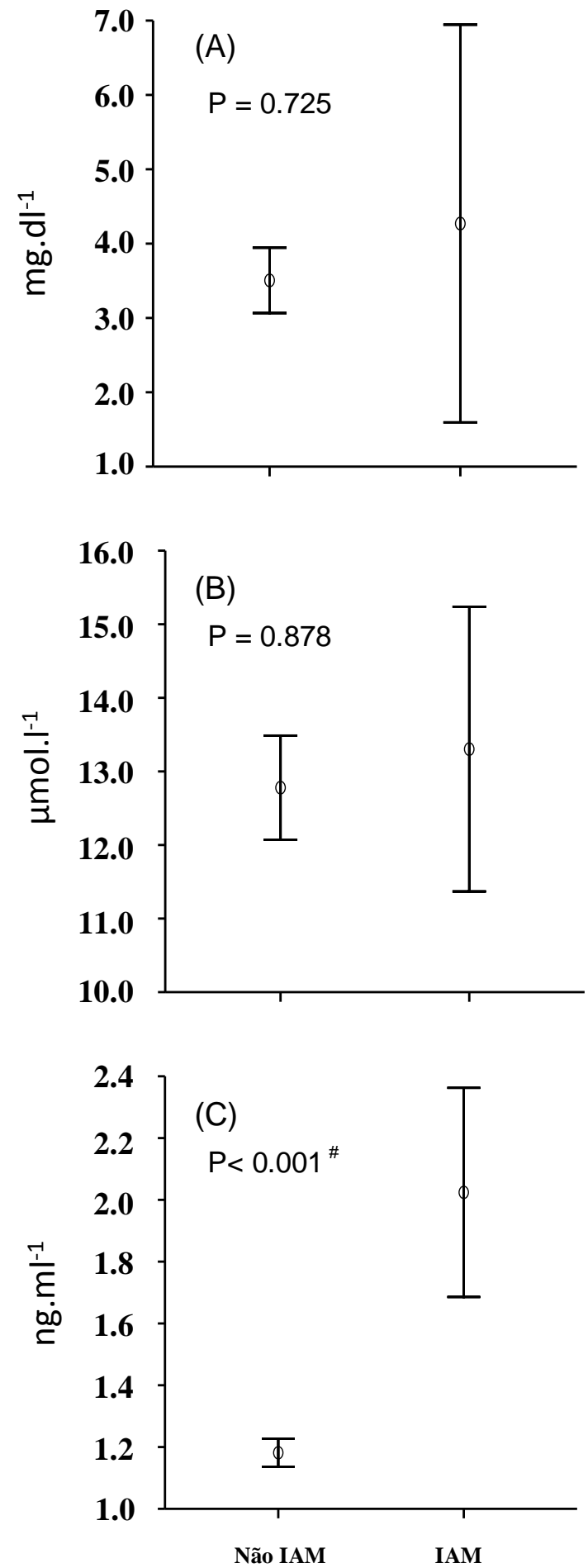

FIGURA 1. Comparação dos níveis circulantes de proteína C-reactiva (A), homocisteína (B) e Klotho (C) entre os indivíduos que apresentavam infarto agudo do miocárdio (IAM) prévio ou não. A significância foi verificada por meio do teste $T$ Student. As barras verticais representam intervalos de um erro padrão. 
Ao analisar a multiplicidade de fatores clássicos de risco clínico, antropométrico e bioquímico para eventos vasculares, juntamente com os mediadores séricos investigados, a regressão multivariada stepwise mostrou que os níveis de Klotho consistiu na variável mais preditiva no modelo $\left(R^{2}=0,086\right)$, e representou $29,3 \%$ da variação na ocorrência de infarto agudo do miocárdio na amostra. 


\section{DISCUSSÃO}

Nosso estudo sugere que Klotho sérico pode constituir marcador independente para indivíduos idosos que apresentaram IAM em sua história clínica, haja vista níveis notoriamente elevados do mediador entre acometidos. Ao nosso conhecimento, este é o primeiro relato acerca de tal associação. No entanto, níveis séricos de Klotho já foram associados com diferentes fatores de risco cardiovasculares em humanos como aterosclerose, estresse oxidativo e disfunção endotelial $(48,50,63,76)$. Tomados em conjunto, a maioria dos achados da literatura sugere que níveis séricos aumentados de Klotho exercem um papel na suscetibilidade a distúrbios metabólicos que têm implicações vasculares. Curiosamente, as nossas análises qualitativa e quantitativamente que retratam características metabólicas (pressórica, lipêmicas, glicêmica) dos idosos em todos haplótipos ou níveis séricos de Klotho não mostraram associação significativa. Também não foram encontradas associações quando consideradas as medidas antropométricas clássicas, as características de estilo de vida e práticas de cuidados de saúde. Estas evidências nos levam a concluir que Klotho não se relaciona com o (e pode não ser um protagonista importante no) desenvolvimento de transtornos e eventos vasculares. Em vez disso, nós supomos que Klotho pode ser um elemento fisiopatológico até agora despercebido ligado ao estado pós-infarto do miocárdio.

Neste contexto, sabe-se que ocorre dilatação ventricular na fase aguda (ventriculomegalia) após IAM, assim como dilatação cavitária tardia em função de hipertrofia excêntrica $(77,78)$, em um processo de adaptação em que o coração tende a uma configuração esférica devido à redistribuição de forças para manutenção da função ventricular em contraposição ao aumento do estresse parietal (maior tensão parietal na diástole do que na sístole) (79-81). Corações hipertrofiados em modelo animal apresentam expressão aumentada de canais TRPC6 (transient receptor potential canonical 6), cuja expressão é regulada por diferentes tipos e intensidades de tensões. Klotho solúvel é conhecido por inibir os canais cardíacos TRPC6, e assim proteger o miocárdio contra uma remodelação excessiva/patológica (82). Desta forma, é plausível que níveis de Klotho elevados no pós-infarto figurem como mecanismo de adaptação ao evento em humanos, 
corroborando com os dados encontrados em nosso estudo. Em favor desta lógica que sugere propriedades benéficas para Klotho, os estudos mostram que a transfecção adenovírus-mediada do gene em modelo animal melhora a disfunção vascular endotelial e previne hipertrofia medial miocárdica $(76,83)$. Contudo, desconhecemos na literatura pesquisas que encontraram associação dos níveis séricos de Klotho em humanos infartados.

Dentre as funções já mencionadas, Klotho também pode atuar na maturação dos adipócitos e no metabolismo de glicose. Estudos mostraram que ratos que não expressam Klotho são resistentes à obesidade, mesmo quando submetidos a uma dieta hiperlipídica $(84,85)$. Com a finalidade de controlar estas covariáveis potenciais, investigamos a ingestão calórica total assim como proporcional aos macronutrientes consumidos por nossa amostra a partir de sua dieta habitual. Entretanto, nossos resultados não indicaram interação importante entre o perfil alimentar e os níveis séricos de Klotho. Sendo assim, a princípio desconsideramos a possibilidade de o padrão alimentar ser responsável pelas variações nos níveis dos mediadores investigados.

Embora os pacientes com grande remodelação do miocárdio relacionados com infarto mostrem piora progressiva da função cardíaca, ainda não há um marcador confiável para tal processo, bem como ainda é um desafio retardar ou reverter a remodelação na prática clínica de indivíduos pós-IAM. No entanto, poucos são os estudos neste campo, e controvérsias (se houver) podem surgir de fatores de confusão não adequadamente investigados ou controlados. A este respeito, o nosso trabalho oferece uma contribuição, assegurando que Klotho circulante não variasse sob a influência de fatores clássicos de risco para eventos vasculares (por ex :: glicêmicos e lipêmicos) ou conforme outros biomarcadores atualmente utilizados na prática clínica (PC-R e homocisteína). Não fomos capazes de excluir da nossa amostra indivíduos que consumiram medicamentos anti-hipertensivos, hipoglicemiantes ou hipolipemiantes (> $85 \%$ da amostra). Mas nossas análises demonstraram que essas terapias não alteraram quaisquer dos biomarcadores estudados. No entanto, existem limitações em nosso estudo que valem a pena ser mencionados. Inicialmente, trata-se de estudo transversal que pode sofrer influência pelo tempo decorrido desde o infarto, que não foi mensurado em nossa investigação. Além disso, o número total de indivíduos foi limitado para se detectar 
diferenças pequenas nas associações estudadas. Por exemplo, os nossos resultados não mostraram diferenças significativas relacionadas com o IAM e níveis de PC-R, com a análise post hoc de poder com base em nossa própria amostra demonstrando que apenas uma amostra de 1116 indivíduos seria capaz de fornecer suficiente poder estatístico $[d=0,20(-0,19 ; 0,59)]$ para detectar diferenças modestas desta variável entre grupos. Mas no que diz respeito a níveis de Klotho, é notável que um razoável efeito tenha sido alcançado na análise de correlação $[d=$ $0,22(0,1-0,4)$ ] para o tamanho da amostra presente, de 168 indivíduos. Portanto, os resultados de nosso estudo poderiam ser interpretados como dotados de poder suficientemente adequado para detectar diferenças significativas. 


\section{CONCLUSÃO}

Nossos resultados sugerem que Klotho sérico apresenta-se elevado em indivíduos pós-infartados. Fatores de risco clássicos para doenças cardiovasculares não apresentaram associação com Klotho sérico, tampouco com suas principais variações genéticas. Propuzemos assim, que a elevação de Klotho no pós-infarto pode refletir um mecanismo de compensação pela hipertrofia miocárdica decorrente. Contudo, mais estudos são necessários para avaliar os mecanismos fisiopatológicos que elevam Klotho sérico nesses indivíduos. 


\section{REFERÊNCIAS}

1. The top 10 causes of death: Fact Sheet No310 [Internet]. WHO. 2014 [cited June 2015].

2. Widimsky P, Wijns W, Fajadet J, de Belder M, Knot J, Aaberge L, et al. Reperfusion therapy for ST elevation acute myocardial infarction in Europe: description of the current situation in 30 countries. European heart journal. 2010 Apr;31(8):943-57. PubMed PMID: 19933242. Pubmed Central PMCID: 2854523.

3. Sistema de Informações sobre Mortalidade-SIM. [Internet]. MS/SVS/DASIS. [cited 10 set. 2015].

4. Bandyopadhyay S, Bayer AJ, O'Mahony MS. Age and gender bias in statin trials. QJM : monthly journal of the Association of Physicians. 2001 Mar;94(3):127-32. PubMed PMID: 11259687.

5. Roger VL, Weston SA, Killian JM, Pfeifer EA, Belau PG, Kottke TE, et al. Time trends in the prevalence of atherosclerosis: a population-based autopsy study. Am J Med. 2001 Mar;110(4):267-73. PubMed PMID: 11239844. Epub 2001/03/10. eng.

6. Nair AP, Darrow B. Lipid management in the geriatric patient. Endocrinol Metab Clin North Am. 2009 Mar;38(1):185-206. PubMed PMID: 19217519. Epub 2009/02/17. eng.

7. Kannel WB, Wilson PW. An update on coronary risk factors. The Medical clinics of North America. 1995 Sep;79(5):951-71. PubMed PMID: 7674694.

8. Tracy RE, Newman WP, 3rd, Wattigney WA, Berenson GS. Risk factors and atherosclerosis in youth autopsy findings of the Bogalusa Heart Study. The American journal of the medical sciences. 1995 Dec;310 Suppl 1:S37-41. PubMed PMID: 7503122.

9. Brotons C, Ribera A, Perich RM, Abrodos D, Magana P, Pablo S, et al. Worldwide distribution of blood lipids and lipoproteins in childhood and adolescence: a review study. Atherosclerosis. 1998 Jul;139(1):1-9. PubMed PMID: 9699886.

10. Mallika V, Goswami B, Rajappa M. Atherosclerosis pathophysiology and the role of novel risk factors: a clinicobiochemical perspective. Angiology. 2007 Oct-Nov;58(5):513-22. PubMed PMID: 18024933.

11. Ross R. The pathogenesis of atherosclerosis: a perspective for the 1990s. Nature. 1993 Apr 29;362(6423):801-9. PubMed PMID: 8479518.

12. Ross R. Atherosclerosis--an inflammatory disease. The New England journal of medicine. 1999 Jan 14;340(2):115-26. PubMed PMID: 9887164.

13. Ross R, Glomset JA. Atherosclerosis and the arterial smooth muscle cell: Proliferation of smooth muscle is a key event in the genesis of the lesions of atherosclerosis. Science. 1973 Jun 29;180(4093):1332-9. PubMed PMID: 4350926.

14. AHA. My Heart and Stroke News2015 August 16, 2015.

15. Thygesen K, Alpert JS, Jaffe AS, Simoons ML, Chaitman BR, White HD, et al. Third universal definition of myocardial infarction. European heart journal. 2012 Oct;33(20):255167. PubMed PMID: 22922414.

16. Bonamigo TL, Lucas ML. Análise crítica das indicações e resultados do tratamento cirúrgico da doenca carotídea. J Vasc Bras. 2007 2007;6(4):366-77. Português.

17. Illuminati G, Calio FG, Papaspyropoulos V, Montesano G, D'Urso A. Revascularization of the internal carotid artery for isolated, stenotic, and symptomatic kinking. Archives of surgery. 2003 Feb;138(2):192-7. PubMed PMID: 12578419. 
18. Mourgela S, Anagnostopoulou S, Sakellaropoulos A, Spanos A. Dolichoectatic cervical arteries (carotid and vertebral arteries) heralded by recurrent cerebral ischemia: case illustration. Angiology. 2008 Feb-Mar;59(1):107-10. PubMed PMID: 18319231.

19. Giroud M, Lemesle M, Madinier G, Manceau E, Osseby GV, Dumas R. Stroke in children under 16 years of age. Clinical and etiological difference with adults. Acta neurologica Scandinavica. 1997 Dec;96(6):401-6. PubMed PMID: 9449480.

20. Kenet G, Sadetzki S, Murad H, Martinowitz U, Rosenberg N, Gitel S, et al. Factor V Leiden and antiphospholipid antibodies are significant risk factors for ischemic stroke in children. Stroke; a journal of cerebral circulation. 2000 Jun;31(6):1283-8. PubMed PMID: 10835445.

21. Lanthier S, Carmant L, David M, Larbrisseau A, de Veber G. Stroke in children: the coexistence of multiple risk factors predicts poor outcome. Neurology. 2000 Jan 25;54(2):371-8. PubMed PMID: 10668698.

22. Bowden AC. Metabolic control analysis in biotechnology and medicine. Nat Biotech. 1999 07//print;17(7):641-3.

23. Bleil SI. O Padrão Alimentar Ocidental: considerações sobre a mudança de hábitos no Brasil ( The western food standard: considerations about the changes in food habits in Brazil). Revista Cadernos de Debate. 1998;VI:1-25. Pt.

24. Garcia RWD. Reflexos da globalização na cultura alimentar: considerações sobre as mudanças na alimentação urbana (Effects of globalization on food culture: considerations on urban food changes). Revista de Nutrição. 2003 out./dez.;16(4):483-92. Pt.

25. Lottenberg AMP. Importância da gordura alimentar na prevenção e no controle de distúrbios metabólicos e da doença cardiovascular. Arq Bras Endocrinol Metab. 2009;53(5):595-607. Pt.

26. Trumbo P, Schlicker S, Yates AA, Poos M, Food, Nutrition Board of the Institute of Medicine TNA. Dietary reference intakes for energy, carbohydrate, fiber, fat, fatty acids, cholesterol, protein and amino acids. Journal of the American Dietetic Association. 2002 Nov;102(11):1621-30. PubMed PMID: 12449285.

27. Sirtori CR, Tremoli E, Gatti E, Montanari G, Sirtori M, Colli S, et al. Controlled evaluation of fat intake in the Mediterranean diet: comparative activities of olive oil and corn oil on plasma lipids and platelets in high-risk patients. The American journal of clinical nutrition. 1986 Nov;44(5):635-42. PubMed PMID: 3094360.

28. Sposito AC, Caramelli B, Fonseca FAH, Bertolami MC, Afiune Neto A, Souza AD, et al. IV Diretriz Brasileira sobre Dislipidemias e Prevenção da Aterosclerose: Departamento de Aterosclerose da Sociedade Brasileira de Cardiologia. Arquivos brasileiros de cardiologia. 2007;88:2-19.

29. Bang HO, Dyerberg J, Sinclair HM. The composition of the Eskimo food in north western Greenland. The American journal of clinical nutrition. 1980 Dec;33(12):2657-61. PubMed PMID: 7435433.

30. Silva JM SC. Dieta, Aterosclerose e Complicações Aterotrombóticas. Rev Port Cardiol. 2007;26(3):277-94. Pt.

31. Hansson GK, Libby P. The immune response in atherosclerosis: a double-edged sword. Nature reviews Immunology. 2006 Jul;6(7):508-19. PubMed PMID: 16778830.

32. Manolio TA, Pearson TA, Wenger NK, Barrett-Connor E, Payne GH, Harlan WR. Cholesterol and heart disease in older persons and women. Review of an NHLBI workshop. Annals of epidemiology. 1992 Jan-Mar;2(1-2):161-76. PubMed PMID: 1342259.

33. Corti MC, Barbato GM, Baggio G. Lipoprotein alterations and atherosclerosis in the elderly. Current opinion in lipidology. 1997 Aug;8(4):236-41. PubMed PMID: 9253541. 
34. Sposito AC CB, Fonseca FAH, Bertolami MC, Afiune Neto A, Souza AD et al . IV Diretriz Brasileira sobre Dislipidemias e Prevenção da Aterosclerose: Departamento de Aterosclerose da Sociedade Brasileira de Cardiologia. Arquivos brasileiros de cardiologia. 2007;88(Suppl 1):2-19. Pt.

35. Wald DS, Law M, Morris JK. Homocysteine and cardiovascular disease: evidence on causality from a meta-analysis. Bmj. 2002 Nov 23;325(7374):1202. PubMed PMID: 12446535. Pubmed Central PMCID: 135491.

36. Francisco G, Hernandez C, Simo R. Serum markers of vascular inflammation in dyslipemia. Clinica chimica acta; international journal of clinical chemistry. $2006 \mathrm{Jul}$ 15;369(1):1-16. PubMed PMID: 16469304.

37. Grundy SM, Cleeman JI, Daniels SR, Donato KA, Eckel RH, Franklin BA, et al. Diagnosis and management of the metabolic syndrome: an American Heart Association/National Heart, Lung, and Blood Institute Scientific Statement. Circulation. 2005 Oct 25;112(17):2735-52. PubMed PMID: 16157765.

38. National Cholesterol Education Program Expert Panel on Detection E, Treatment of High Blood Cholesterol in A. Third Report of the National Cholesterol Education Program (NCEP) Expert Panel on Detection, Evaluation, and Treatment of High Blood Cholesterol in Adults (Adult Treatment Panel III) final report. Circulation. 2002 Dec 17;106(25):3143-421. PubMed PMID: 12485966.

39. Wilson PW, D'Agostino RB, Levy D, Belanger AM, Silbershatz H, Kannel WB. Prediction of coronary heart disease using risk factor categories. Circulation. 1998 May 12;97(18):1837-47. PubMed PMID: 9603539.

40. Boushey CJ, Beresford SA, Omenn GS, Motulsky AG. A quantitative assessment of plasma homocysteine as a risk factor for vascular disease. Probable benefits of increasing folic acid intakes. Jama. 1995 Oct 4;274(13):1049-57. PubMed PMID: 7563456.

41. Graham IM, Daly LE, Refsum HM, Robinson K, Brattstrom LE, Ueland PM, et al. Plasma homocysteine as a risk factor for vascular disease. The European Concerted Action Project. Jama. 1997 Jun 11;277(22):1775-81. PubMed PMID: 9178790.

42. Kang SS, Zhou J, Wong PW, Kowalisyn J, Strokosch G. Intermediate homocysteinemia: a thermolabile variant of methylenetetrahydrofolate reductase. American journal of human genetics. 1988 Oct;43(4):414-21. PubMed PMID: 3177384. Pubmed Central PMCID: 1715503.

43. Selhub J, Jacques PF, Wilson PW, Rush D, Rosenberg IH. Vitamin status and intake as primary determinants of homocysteinemia in an elderly population. Jama. 1993 Dec 8;270(22):2693-8. PubMed PMID: 8133587.

44. Diniz-Santos DR, Andrade GCFd. A homocisteína como fator de risco para aterosclerose. R Ci méd biol. 2005;4(2):158-66. Epub mai./ago. 2005. Português.

45. Vlachopoulos C, Xaplanteris P, Aboyans V, Brodmann M, Cifkova R, Cosentino F, et al. The role of vascular biomarkers for primary and secondary prevention. A position paper from the European Society of Cardiology Working Group on peripheral circulation: Endorsed by the Association for Research into Arterial Structure and Physiology (ARTERY) Society. Atherosclerosis. 2015 Aug;241(2):507-32. PubMed PMID: 26117398.

46. Piegas L, Timerman A, Feitosa G, Nicolau J, Mattos L, Andrade M, et al. V Diretriz da Sociedade Brasileira de Cardiologia sobre Tratamento do Infarto Agudo do Miocárdio com Supradesnível do Segmento ST. Arquivos brasileiros de cardiologia. 2015;105:1-121.

47. de Miranda MR, Lima LM. Biochemical markers of acute myocardial infarction. Rev Med Minas Gerais. 2014;24(1):95-102. 
48. Kuro-o M, Matsumura Y, Aizawa H, Kawaguchi H, Suga T, Utsugi T, et al. Mutation of the mouse klotho gene leads to a syndrome resembling ageing. Nature. 1997 Nov 6;390(6655):45-51. PubMed PMID: 9363890.

49. Shiraki-Iida T, Aizawa H, Matsumura Y, Sekine S, Iida A, Anazawa H, et al. Structure of the mouse klotho gene and its two transcripts encoding membrane and secreted protein 1. FEBS Letters. 1998 3/6/;424(1-2):6-10.

50. Kurosu H, Yamamoto M, Clark JD, Pastor JV, Nandi A, Gurnani P, et al. Suppression of aging in mice by the hormone Klotho. Science. 2005 Sep 16;309(5742):1829-33. PubMed PMID: 16123266. Pubmed Central PMCID: 2536606.

51. Matsumura Y, Aizawa H, Shiraki-Iida T, Nagai R, Kuro-o M, Nabeshima Y. Identification of the human klotho gene and its two transcripts encoding membrane and secreted klotho protein. Biochemical and biophysical research communications. 1998 Jan 26;242(3):626-30. PubMed PMID: 9464267.

52. Arking DE, Becker DM, Yanek LR, Fallin D, Judge DP, Moy TF, et al. KLOTHO allele status and the risk of early-onset occult coronary artery disease. American journal of human genetics. 2003 May;72(5):1154-61. PubMed PMID: 12669274. Pubmed Central PMCID: 1180268.

53. Rhee EJ, Oh KW, Lee WY, Kim SY, Jung CH, Kim BJ, et al. The differential effects of age on the association of KLOTHO gene polymorphisms with coronary artery disease. Metabolism: clinical and experimental. 2006 Oct;55(10):1344-51. PubMed PMID: 16979405. 54. Kuro-o M. Klotho in chronic kidney disease--what's new? Nephrology, dialysis, transplantation : official publication of the European Dialysis and Transplant Association European Renal Association. 2009 Jun;24(6):1705-8. PubMed PMID: 19225012.

55. Kuro-o M. Overview of the FGF23-Klotho axis. Pediatric nephrology. 2010 Apr;25(4):583-90. PubMed PMID: 19626341.

56. Hu MC, Shi M, Zhang J, Quinones H, Griffith C, Kuro-o M, et al. Klotho deficiency causes vascular calcification in chronic kidney disease. Journal of the American Society of Nephrology : JASN. 2011 Jan;22(1):124-36. PubMed PMID: 21115613. Pubmed Central PMCID: 3014041.

57. Wang Y, Sun Z. Current understanding of klotho. Ageing research reviews. 2009 Jan;8(1):43-51. PubMed PMID: 19022406. Pubmed Central PMCID: 2637560.

58. Tsujikawa H, Kurotaki Y, Fujimori T, Fukuda K, Nabeshima Y. Klotho, a gene related to a syndrome resembling human premature aging, functions in a negative regulatory circuit of vitamin D endocrine system. Molecular endocrinology. 2003 Dec;17(12):2393-403. PubMed PMID: 14528024.

59. Johnson CS, Muindi JR, Hershberger PA, Trump DL. The antitumor efficacy of calcitriol: preclinical studies. Anticancer research. 2006 Jul-Aug;26(4A):2543-9. PubMed PMID: 16886662.

60. Narvaez CJ, Zinser G, Welsh J. Functions of 1alpha,25-dihydroxyvitamin D(3) in mammary gland: from normal development to breast cancer. Steroids. 2001 Mar-May;66(35):301-8. PubMed PMID: 11179738.

61. Oliveira RB, Okazaki H, Stinghen AEM, Drueke TB, Massy ZA, Jorgetti V. Calcificação vascular em doença renal crônica: uma revisão. J Bras Nefrol. 2013;35(2):14761. Pt.

62. Arking DE, Atzmon G, Arking A, Barzilai N, Dietz HC. Association between a functional variant of the KLOTHO gene and high-density lipoprotein cholesterol, blood pressure, stroke, and longevity. Circulation research. 2005 Mar 4;96(4):412-8. PubMed PMID: 15677572. 
63. Saito Y, Yamagishi T, Nakamura T, Ohyama Y, Aizawa H, Suga T, et al. Klotho protein protects against endothelial dysfunction. Biochemical and biophysical research communications. 1998 Jul 20;248(2):324-9. PubMed PMID: 9675134.

64. Fukino K, Suzuki T, Saito Y, Shindo T, Amaki T, Kurabayashi M, et al. Regulation of angiogenesis by the aging suppressor gene klotho. Biochemical and biophysical research communications. 2002 Apr 26;293(1):332-7. PubMed PMID: 12054604.

65. Physical Activity Guidelines Advisory Committee report, 2008. To the Secretary of Health and Human Services. Part A: executive summary. Nutrition reviews. 2009 Feb;67(2):114-20. PubMed PMID: 19178654.

66. Backinger CL, Fagan P, O'Connell ME, Grana R, Lawrence D, Bishop JA, et al. Use of other tobacco products among U.S. adult cigarette smokers: prevalence, trends and correlates. Addictive behaviors. 2008 Mar;33(3):472-89. PubMed PMID: 18053653. Pubmed Central PMCID: 2277213.

67. Lohmann TG, Roche AF, Martorell R. Anthropometric Standardization Reference Manual: Human Kinetics Books, Champaign, Ill.; 1988.

68. Expert Panel on Detection E, Treatment of High Blood Cholesterol in A. Executive Summary of The Third Report of The National Cholesterol Education Program (NCEP) Expert Panel on Detection, Evaluation, And Treatment of High Blood Cholesterol In Adults (Adult Treatment Panel III). Jama. 2001 May 16;285(19):2486-97. PubMed PMID: 11368702.

69. American Diabetes A. Standards of medical care in diabetes. Diabetes care. 2005 Jan;28 Suppl 1:S4-S36. PubMed PMID: 15618112.

70. Sociedade Brasileira de C, Sociedade Brasileira de H, Sociedade Brasileira de N. [VI Brazilian Guidelines on Hypertension]. Arquivos brasileiros de cardiologia. 2010 Jul;95(1 Suppl):1-51. PubMed PMID: 21085756. VI Diretrizes Brasileiras de hipertensao.

71. Matthews DR, Hosker JP, Rudenski AS, Naylor BA, Treacher DF, Turner RC. Homeostasis model assessment: insulin resistance and beta-cell function from fasting plasma glucose and insulin concentrations in man. Diabetologia. 1985 Jul;28(7):412-9. PubMed PMID: 3899825.

72. Philippi ST. Tabela de composição de alimentos: suporte para decisão nutricional. 2 nd ed. São Paulo- Brasil: Coronário; 20022002.

73. Folstein MF, Folstein SE, McHugh PR. "Mini-mental state". A practical method for grading the cognitive state of patients for the clinician. Journal of psychiatric research. 1975 Nov;12(3):189-98. PubMed PMID: 1202204.

74. Castro-Costa E, Fuzikawa C, Uchoa E, Firmo JO, Lima-Costa MF. Norms for the mini-mental state examination: adjustment of the cut-off point in population-based studies (evidences from the Bambui health aging study). Arquivos de neuro-psiquiatria. 2008 Sep;66(3A):524-8. PubMed PMID: 18813712.

75. Arking DE, Krebsova A, Macek M, Sr., Macek M, Jr., Arking A, Mian IS, et al. Association of human aging with a functional variant of klotho. Proceedings of the National Academy of Sciences of the United States of America. 2002 Jan 22;99(2):856-61. PubMed PMID: 11792841. Pubmed Central PMCID: 117395.

76. Saito Y, Nakamura T, Ohyama Y, Suzuki T, Iida A, Shiraki-Iida T, et al. In vivo klotho gene delivery protects against endothelial dysfunction in multiple risk factor syndrome. Biochemical and biophysical research communications. 2000 Sep 24;276(2):767-72. PubMed PMID: 11027545.

77. Anversa P, Loud AV, Levicky V, Guideri G. Left ventricular failure induced by myocardial infarction. II. Tissue morphometry. The American journal of physiology. 1985 Jun;248(6 Pt 2):H883-9. PubMed PMID: 3159269. 
78. Anversa P, Sonnenblick EH. Ischemic cardiomyopathy: pathophysiologic mechanisms. Progress in cardiovascular diseases. 1990 Jul-Aug;33(1):49-70. PubMed PMID: 2142312.

79. Cohn JN, Ferrari R, Sharpe N. Cardiac remodeling--concepts and clinical implications: a consensus paper from an international forum on cardiac remodeling. Behalf of an International Forum on Cardiac Remodeling. Journal of the American College of Cardiology. 2000 Mar 1;35(3):569-82. PubMed PMID: 10716457.

80. Pfeffer MA, Braunwald E. Ventricular remodeling after myocardial infarction. Experimental observations and clinical implications. Circulation. 1990 Apr;81(4):1161-72. PubMed PMID: 2138525.

81. Zornoff LA, Spadaro J. [Ventricular remodeling after acute myocardial infarction. Concepts, pathophysiology and therapeutic approach]. Arquivos brasileiros de cardiologia. 1997 Jun;68(6):453-60. PubMed PMID: 9515254. Remodelacao ventricular apos infarto agudo do miocardio. Conceitos, fisiopatologia e abordagem terapeutica.

82. Frey N, Katus HA, Olson EN, Hill JA. Hypertrophy of the heart: a new therapeutic target? Circulation. 2004 Apr 6;109(13):1580-9. PubMed PMID: 15066961.

83. Yang J, Matsukawa N, Rakugi H, Imai M, Kida I, Nagai M, et al. Upregulation of cAMP is a new functional signal pathway of Klotho in endothelial cells. Biochemical and biophysical research communications. 2003 Feb 7;301(2):424-9. PubMed PMID: 12565878.

84. Ohnishi M, Kato S, Akiyoshi J, Atfi A, Razzaque MS. Dietary and genetic evidence for enhancing glucose metabolism and reducing obesity by inhibiting klotho functions. FASEB journal : official publication of the Federation of American Societies for Experimental Biology. 2011 Jun;25(6):2031-9. PubMed PMID: 21382979. Pubmed Central PMCID: 3101030.

85. Razzaque MS. The role of Klotho in energy metabolism. Nature reviews Endocrinology. 2012 Oct;8(10):579-87. PubMed PMID: 22641000. Pubmed Central PMCID: 3704949.

86. Pankow JS, Folsom AR, Cushman M, Borecki IB, Hopkins PN, Eckfeldt JH, et al. Familial and genetic determinants of systemic markers of inflammation: the NHLBI family heart study. Atherosclerosis. 2001;154(3):681-9. 
ANEXO A- PARECER DO COMITÊ DE ÉTICA E PESQUISA

UNIVERSIDADE DE BRASILIA

FACULDADE DE MEDICINA

Comitê de Ética em Pesquisa em Seres Humanos

ANAILISE DE PROHETO DE PESQLISA

Registro de Projeto: (EP. FM 06: Z01:

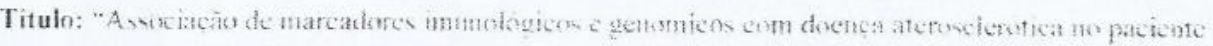
ambulatorial idoso".

Pesquisador Responsável: Otav io de Toledo Notresat.

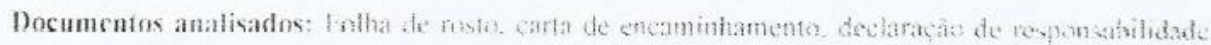

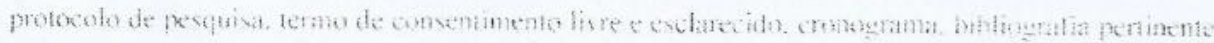
e curriculo (5) de pesquisador (es).

Data de entrega: $2208 / 2011$.

Parecer do (a) relator (a)

(X) Aprosaç̃o

() Vão aprovaç̃o.

Data da primeira análise pelo CFP-FM/L NB: 10102011 .

Data do parecer final do projeto peto CEP-FW/U NB: 2612301 1.

\section{PSRTCFR}

Com base na Resoluça C NS MS n" $1 \% 96$ e resoluços posteriores, que regulameatam a materia. a coordenaçâo do Comitê de fitica em Pesquisa da Faculdade de Medieina da Lni ersidade de Brasifia decidiu APROVAR "ad referendum" do CI.P.FM. conforme parecer do (a) relatur (a). o prajeto de pesquisa acima especificado quanto aos sèus aspectos éticos.

1. Modificaçōes no profocolo detem ser submetidas ao CiP. assim como a novilicaça imediata de eventos adversos yraves:

2. $O$ (s) pesquisador fes) deve (m) apresentar relatórios periodicos do andamento da psosuisa ao CEP FM. sendo o " previsto para 20 de julho de 2012 .

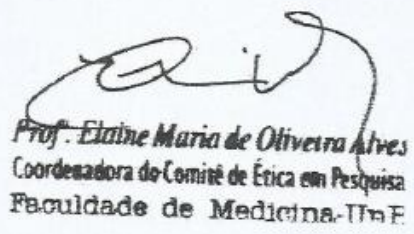




\section{ANEXO B- PROTOCOLO DE ATENDIMENTO CLÍNICO}

HOSPITAL DA UNIVERSIDADE CATÓLICA DE BRASÍLIA - HUCB

Curso de medicina - disciplina de geriatria/gerontologia

FICHA CLÍNICA/ANAMNESE

1. IDENTIFICAÇÃ̃O

Nome

IDADE:

MASC $\square$

Circunf. Abdom.

PESO:

PAS: mmHg

FEM $\square$

DATA NASC: registro: $\mathrm{cm}$

ALTURA:

PAD: m $\mathrm{mmHg}$

IMC: $\left(\mathrm{Kg} / \mathrm{m}^{2}\right)$

\section{COMORBIDADES}
$\square$ HIPERTENSÃO ARTERIAL
$\square$ DISLIPIDEMIA
$\square \mathrm{CA}$
$\square$ AIT
$\square$ DIABETES MELLITUS II
$\square$ AVE
$\square$ IAM
DAC (ANGINA)

Medicamento(s): somente utilização de anti-hipertensivos, anti-diabéticos e hipolipemiantes

\begin{tabular}{|c|c|c|}
\hline Princípio ativo & Posologia & Dose diária \\
\hline & & \\
\hline & & \\
\hline \multicolumn{3}{|l|}{ 3. HISTÓRIA SOCIAL } \\
\hline$\square$ TABAGISMO: POR QTOS ANOS & \multicolumn{2}{|c|}{$\square$ ETILISMO: POR QTOS ANOS } \\
\hline$\square$ SEDENTÁRIO & \multicolumn{2}{|c|}{$\square$ EXERCÍCIOS FÍSICOS REGULARES } \\
\hline
\end{tabular}

\section{EXAMES LABORATORIAIS:}

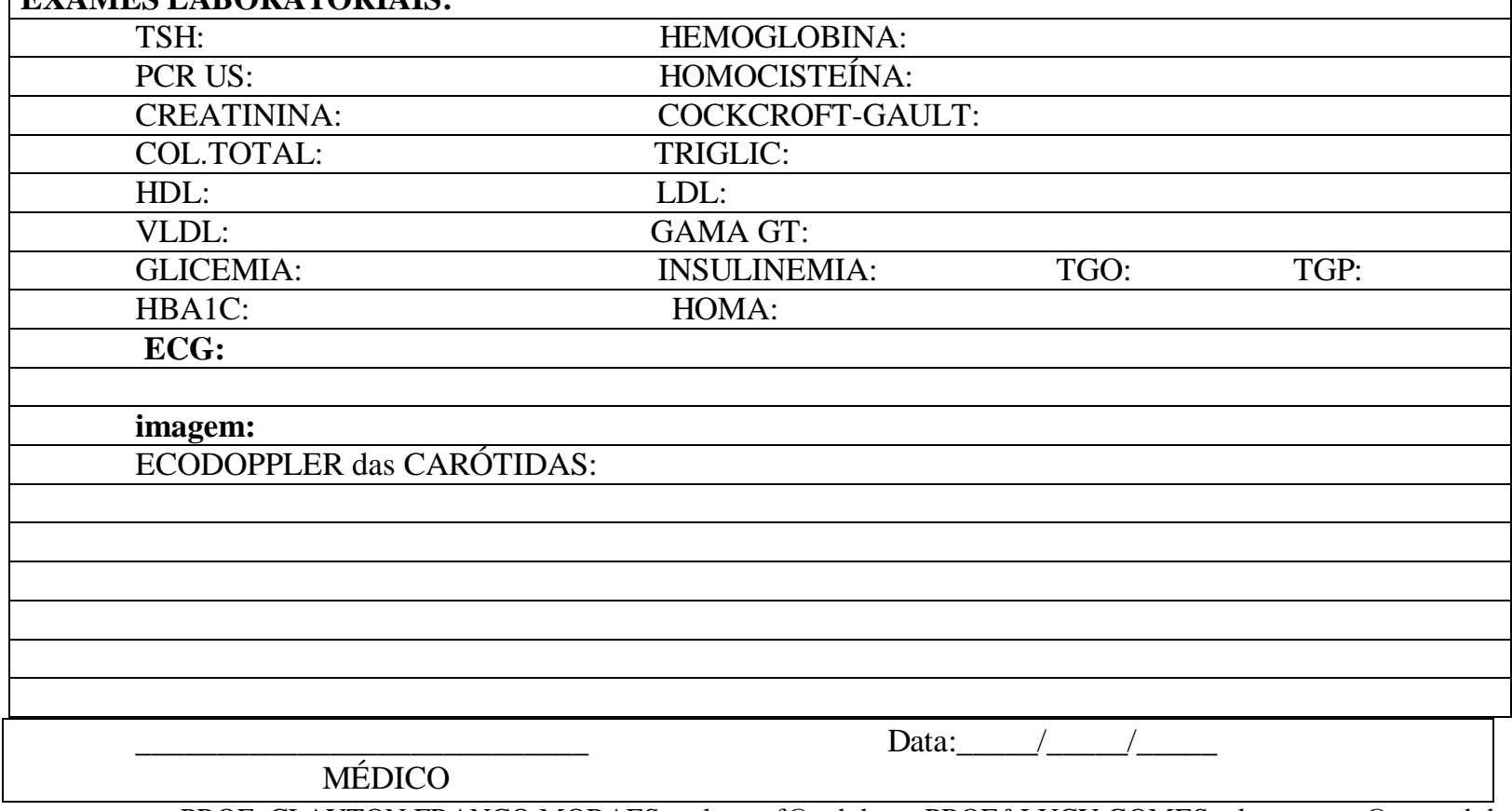

PROF. CLAYTON FRANCO MORAES - claytonf@ucb.br - PROF. ${ }^{a}$ LUCY GOMES - lucygomes@ @os.ucb.br HUCB - QS 05, LOTE 22 - AVENIDA AREAL ÁGUAS CLARAS/DF CEP: 71.955-000 - Telefone: 61-3451-1000 www.hucb.com.br 


\section{ANEXO C- PROTOCOLO DE ATENDIMENTO NUTRICIONAL}

\section{FICHA NUTRICIONAL PARA ANAMNESE ALIMENTAR DE IDOSOS}

DATA: NUTRICIONISTA:

ID:

Nome:

DN:

$\mathrm{Pa}$ Kg Estatura ra Idade:

Escolaridade: m IMC $\mathrm{Kg} / \mathrm{m}^{2} \mathrm{Ca}$ cm

HPP:

\section{Sintomas do TGI:}

( ) constipação. Frequência:

) disfagia. Quais alimentos?

) epigastralgia. Quais alimentos?

) diarréia. Frequência:

) pirose. Frequência:

) plenitude pós-prandial. Frequência:

) flatulência. Frequência:

) fezes normais. Consistência?

) urina. Cor Frequência?

Coloração?

Ingestão hídrica/diária:

FREQUÊNCIA DE CONSUMO ALIMENTAR

REFEIÇÕES REALIZADAS: DESJEJUM - COLAÇÃO- ALMOÇO-MERENDA- JANTAR-CEIA Tem hábito de beliscar entre as refeições?

\begin{tabular}{|c|c|c|c|c|c|c|c|c|c|c|}
\hline \multirow{2}{*}{$\begin{array}{l}\text { GRUPOS DE } \\
\text { ALIMENTOS }\end{array}$} & \multirow{2}{*}{$\begin{array}{l}\mathbf{N}^{\circ} \text { DE } \\
\text { vEZZS }\end{array}$} & \multicolumn{7}{|c|}{ FREQUÊNCIA DE CONSUMO } & \multirow{2}{*}{ RAZÕES } & \multirow[t]{2}{*}{ OBS. } \\
\hline & & D & $\mathbf{S}$ & $\mathbf{Q}$ & $\mathbf{M}$ & $\mathbf{S}$ & A & $\mathbf{N}$ & & \\
\hline \multicolumn{11}{|c|}{ LEITE E DERIVADOS } \\
\hline \multicolumn{11}{|c|}{\begin{tabular}{l|l|l|l} 
Leite & & &
\end{tabular}} \\
\hline \multicolumn{11}{|l|}{ Iogurte } \\
\hline \multicolumn{11}{|l|}{ Queijo } \\
\hline \multicolumn{11}{|l|}{ Manteiga } \\
\hline \multicolumn{11}{|l|}{ Requeijão } \\
\hline \multicolumn{11}{|c|}{ CARNES E OVOS } \\
\hline \multicolumn{11}{|c|}{\begin{tabular}{l|l|l} 
Carne bovina & \\
\end{tabular}} \\
\hline \multicolumn{11}{|l|}{$\overline{\text { Carne suína }}$} \\
\hline \multicolumn{11}{|l|}{ Frango } \\
\hline \multicolumn{11}{|l|}{$\overline{\text { Fígado }}$} \\
\hline \multicolumn{11}{|l|}{ Linguiça } \\
\hline$\overline{\text { Peixe }}$ & & & & & & & & & & \\
\hline
\end{tabular}




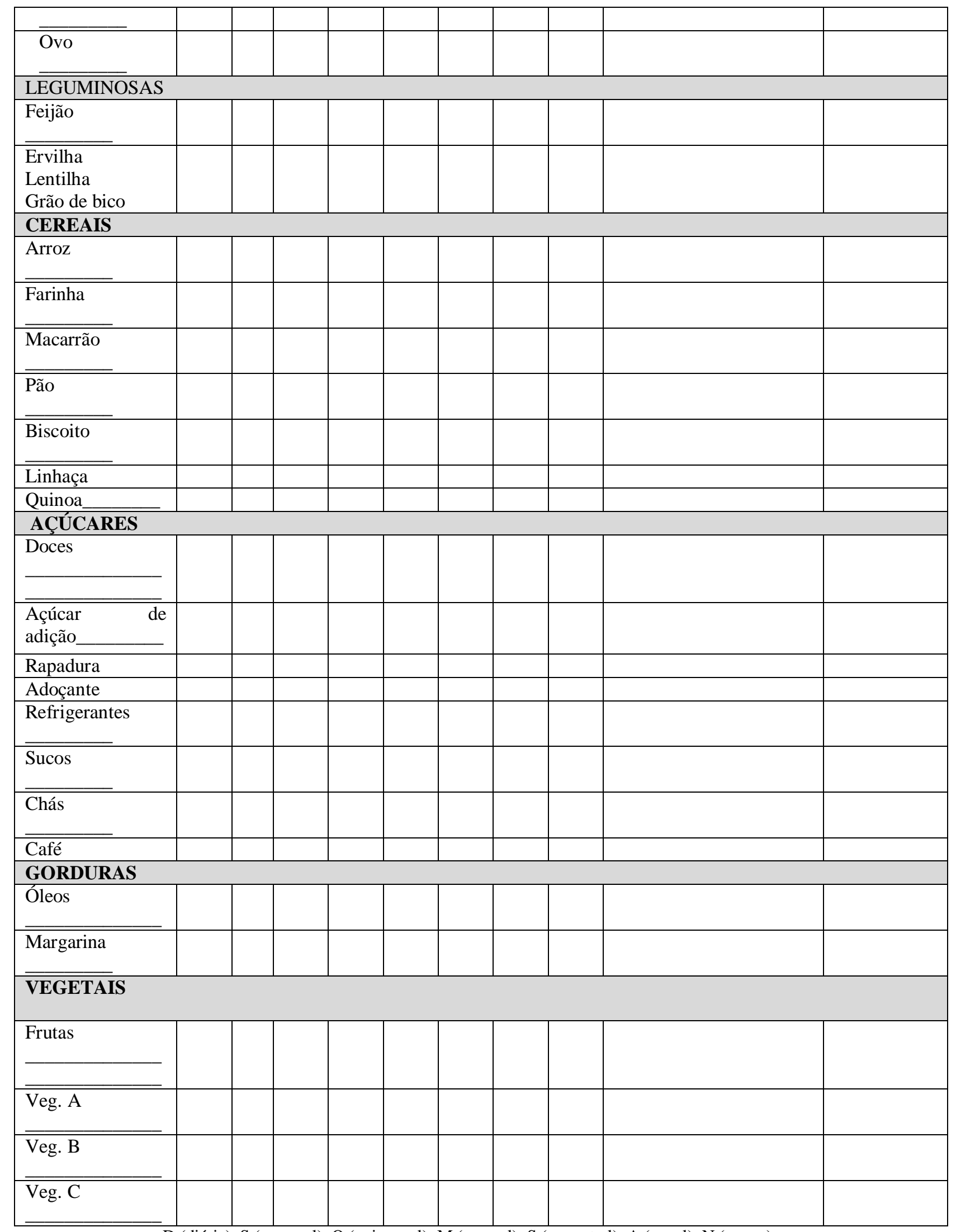

D (diária), S (semanal), Q (quinzenal), M (mensal), S (semestral), A (anual), N (nunca).

Razões para o não consumo ou pouco consumo (frequiências: mensal, semestral, anual ou nunca)

1. Não gosta -2. Preço - 3. Difícil preparo - 4. Não tem hábito - 5. Outras (especificar)

Fonte: adaptado por DUARTE; CASTELLANI, 2002. 
ANEXO D- REGISTRO ALIMENTAR ESTIMADO

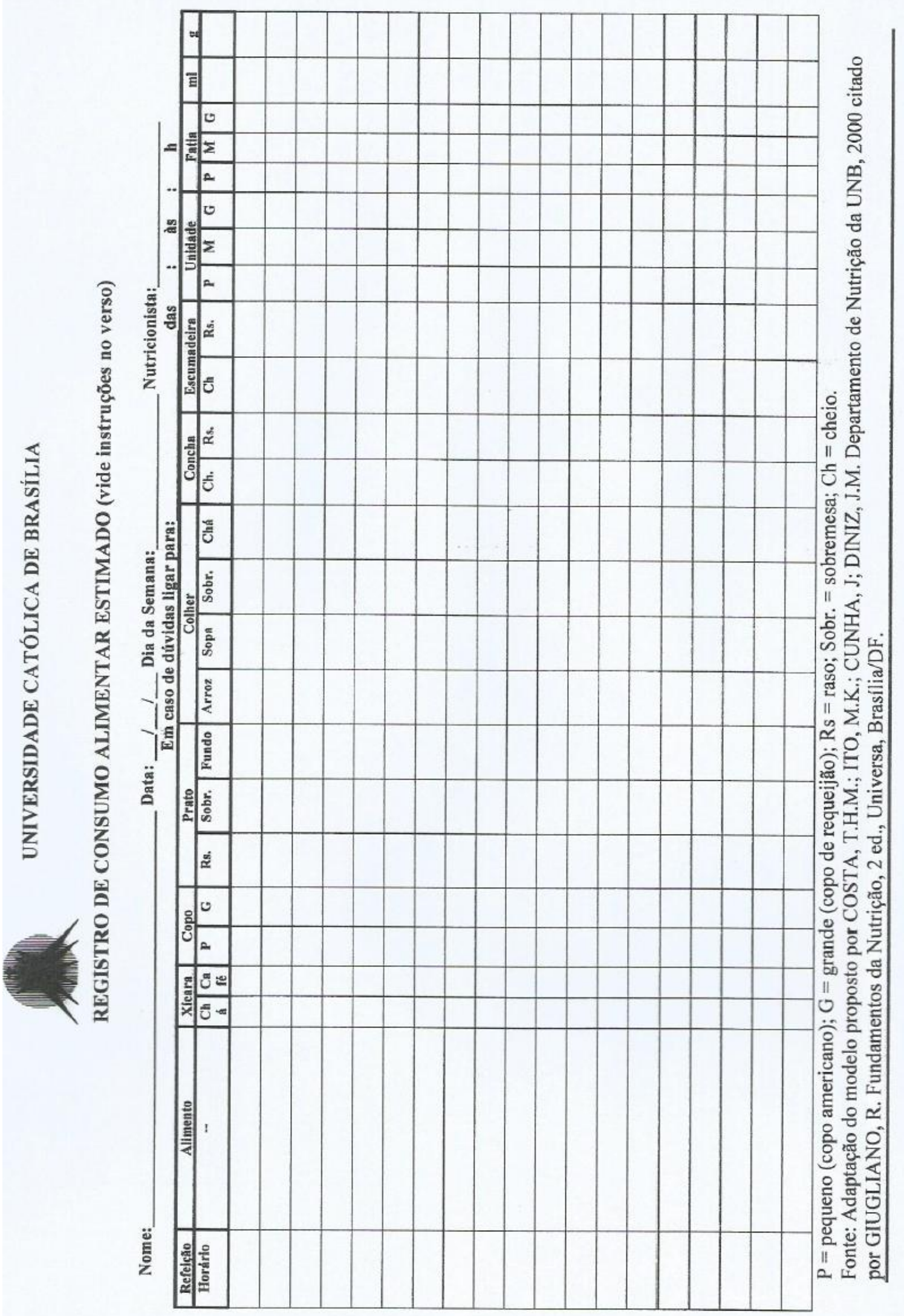




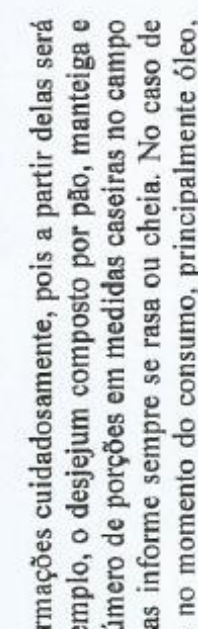

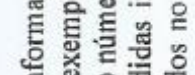

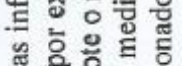

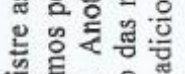

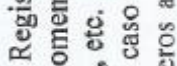

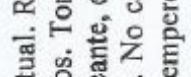

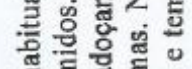

品密总

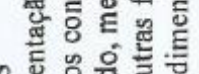

以

을 흘

元 ह气

के

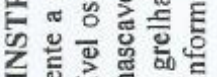

额

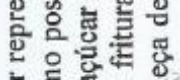

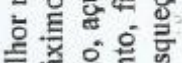

늘 응

드을

흥항

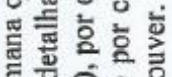

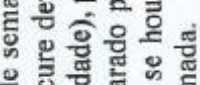

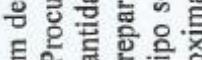

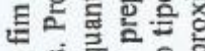

띃

튼융을 뜐

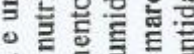

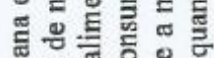

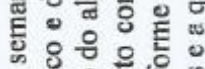

뚠

뜽

응 융

品言

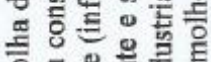

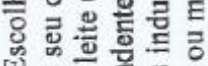

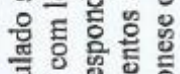

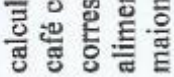

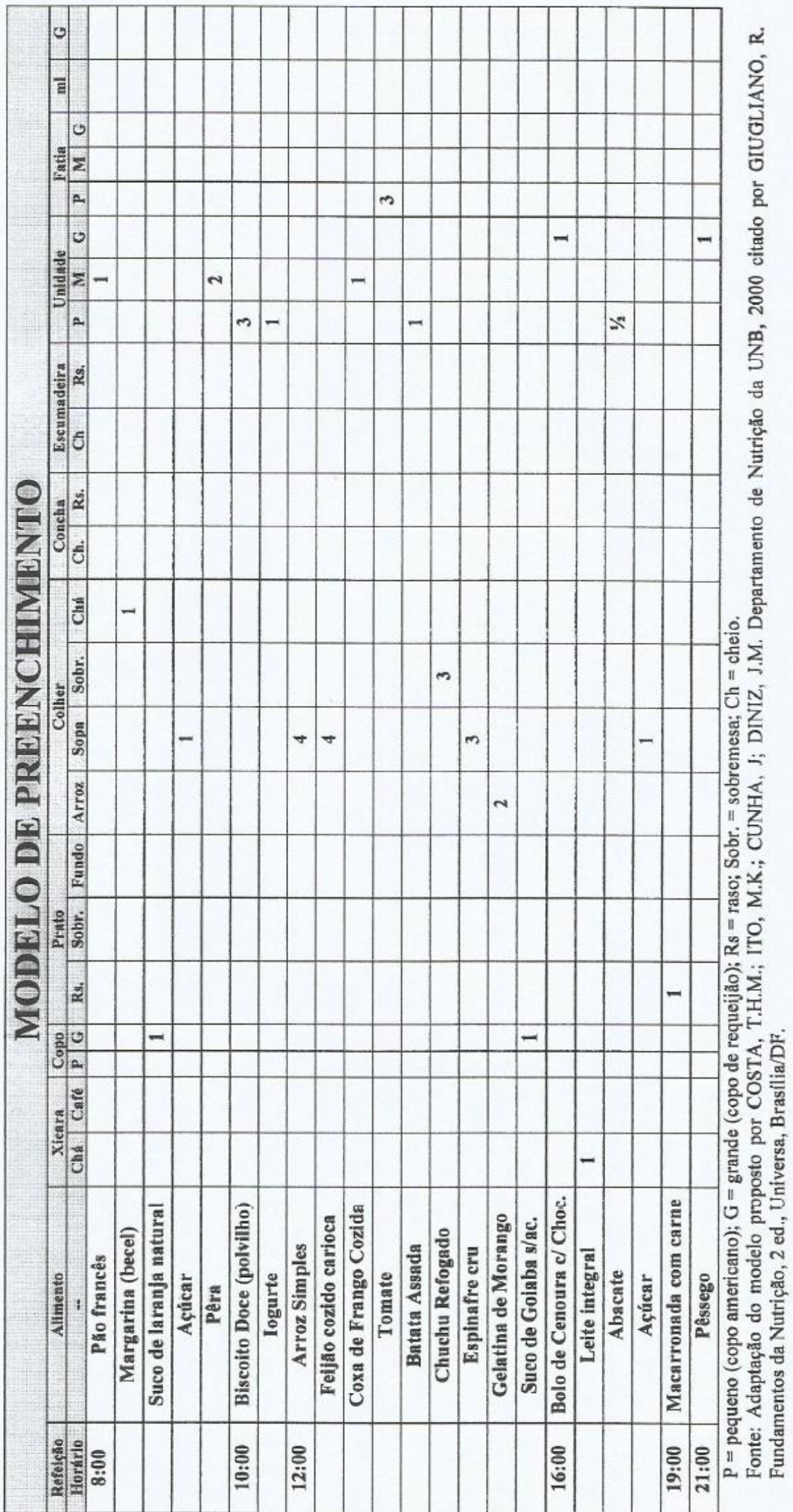


ANEXO E- MINI EXAME DO ESTADO MENTAL

Nome:

Avaliador:

Pront:

Escolaridade/anos:

MINI-EXAME DO ESTADO MENTAL

\begin{tabular}{|c|c|c|}
\hline \multirow{6}{*}{1.} & Orientação temporal- (um ponto para cada resposta correta) & Pontos \\
\hline & Que dia é hoje? & \\
\hline & Em que mês estamos? & \\
\hline & Em que ano estamos? & \\
\hline & Em que dia da semana estamos? & \\
\hline & Qual é a hora aproximada? (considerar uma hora pra mais ou p/ menos) & \\
\hline \multirow[t]{6}{*}{2.} & Orientação espacial- (um ponto para cada resposta correta) & \\
\hline & Em que estado nós estamos? & \\
\hline & Em que cidade-satélite nós estamos? & \\
\hline & Em que Instituição estamos? & \\
\hline & Que ambiente é este aqui? & \\
\hline & Qual é o número da casa ou do apartamento onde você mora? & \\
\hline 3. & $\begin{array}{l}\text { Memória imediata- Eu vou dizer } 3 \text { palavras e você irá repeti-las a seguir: carro, } \\
\text { vaso, tijolo ( } 1 \text { ponto para cada palavra acertadamente na } 1^{\mathrm{a}} \text { vez, embora possa } \\
\text { repeti-la até } 3 \text { vezes para o aprendizado, se houver erros). }\end{array}$ & \\
\hline 4. & 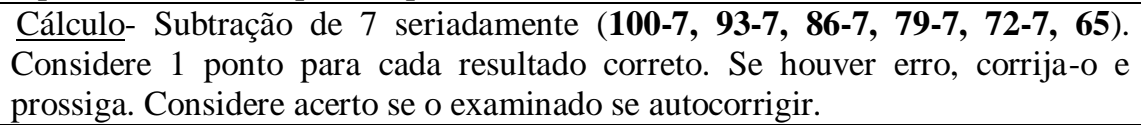 & \\
\hline 5. & $\begin{array}{l}\text { Evocação das palavras- Pergunte quais as palavras que o sujeito acabara de } \\
\text { repetir- } 1 \text { ponto para cada }\end{array}$ & \\
\hline 6. & $\begin{array}{l}\text { Nomeação- Peça para o sujeito nomear os objetos mostrados (relógio, caneta)- } \\
1 \text { ponto para cada }\end{array}$ & \\
\hline 7. & $\begin{array}{l}\text { Repetição- Preste atenção: vou lhe dizer uma frase e quero que você repita } \\
\text { depois de mim: “ Nem aqui, nem ali, nem lá”. Considere somente se a } \\
\text { repetição for perfeita ( } 1 \text { ponto) }\end{array}$ & \\
\hline 8. & $\begin{array}{l}\text { Comando- Pegue este papel com a mão direita ( } 1 \text { ponto), dobre-o ao meio ( } 1 \\
\text { ponto) e coloque-o em cima da mesa ( } 1 \text { ponto). Total de } 3 \text { pontos. Se o sujeito } \\
\text { pedir ajuda no meio da tarefa não dê dicas. }\end{array}$ & \\
\hline 9. & $\begin{array}{l}\text { Leitura- Mostre a frase escrita "FECHE OS OLHOS" e peça para o indivíduo } \\
\text { fazer o que está sendo mandado. Não auxilie se pedir ajuda ou se só ler a frase } \\
\text { sem realizar o comando. }\end{array}$ & \\
\hline 10. & $\begin{array}{l}\text { Frase- Peça ao indivíduo para escrever uma frase. Se não compreender o } \\
\text { significado, ajude com: alguma frase que tenha começo, meio e fim; alguma } \\
\text { coisa que aconteceu hoje; alguma coisa que queira dizer. Para a correção não } \\
\text { são considerados erros gramaticais ou ortográficos ( } 1 \text { ponto) }\end{array}$ & \\
\hline 11. & $\begin{array}{l}\text { Cópia do desenho- Mostre o modelo e peça para fazer o melhor possível. } \\
\text { Considere apenas se houver } 2 \text { pentágonos interseccionados (10 ângulos }) \\
\text { formando uma figura de quatro lados ou com dois ângulos (1 ponto })\end{array}$ & \\
\hline & TOTAL & \\
\hline
\end{tabular}

(BRUCKI et al., 2003) 


\section{ANEXO F- ARTIGO DA TESE}

(E.mail da submissão do artigo da tese)

De: ees.cvp.0.36b673.771d2f36@eesmail.elsevier.com em nome de Cardiovascular Pathology

Para: otnobrega@gmail.com; otavionobrega@unb.br

Assunto: A manuscript number has been assigned: CVP-D-16-00009

Data: segunda-feira, 18 de janeiro de 2016 12:36:44

Ms. Ref. No.: CVP-D-16-00009

Title: Serum Klotho correlates with the post-myocardial infarction status of older adults

Cardiovascular Pathology

Dear Dr. Otávio T. Nóbrega,

Your submission entitled "Serum Klotho correlates with the post-myocardial infarction status of older adults" has been assigned the following manuscript number: CVP-D-1600009.

You may check on the progress of your paper by logging on to the Elsevier Editorial System as an author. The

URL is http://ees.elsevier.com/cvp/.

Your username is: otnobrega@gmail.com

If you need to retrieve password details, please go to:

http://ees.elsevier.com/CVP/automail query.asp

Thank you for submitting your work to this journal.

Kind regards,

Sarah Keith

Editorial Assistant

Cardiovascular Pathology 


\section{Serum Klotho correlates with the post-myocardial infarction status of older adults}

Runninghead: Klotho, vascular risk and old subjects.

Category: Original Article

Roberta Silva Paula ${ }^{1}$, Vinícius Carolino Souza ${ }^{1}$, Wilcelly Machado-Silva ${ }^{1}$, Bruno Ratier

Saconi Almeida ${ }^{1}$, Andersen Charles Daros ${ }^{2}$, Lucy Gomes ${ }^{3}$, Clayton Franco Moraes ${ }^{1,3}$, Ciro José Brito ${ }^{4}$, Cláudio Córdova ${ }^{3}$ and Otávio Toledo Nóbrega ${ }^{1, *}$

${ }^{1}$ Universidade de Brasília (UnB).

${ }^{2}$ Centro Universitário de Brasília (UNICEUB).

${ }^{3}$ Universidade Católica de Brasília (UCB-DF).

${ }^{4}$ Universidade Federal de Juiz de Fora (UFJF).

*Corresponding author: O. T. Nóbrega, Programa de Pós-Graduação em Ciências Médicas, Campus Universitário Darcy Ribeiro, Asa Norte, 70910-900, Brasília - DF, Brazil.Phone: +55-61-3307-2520. E-mail: otavionobrega@unb.br

Total text word count: 3,699 words.

Total abstract word count: 155 words. 


\begin{abstract}
Context and objective: The number of deaths from vascular diseases is incredibly high worldwide, and reliable markers for major events are still needed. This cross-sectional study investigated the association of Klotho haplotypes and of its serum levels with classic risk factors and clinical history of vascular events. Materials and methods: Clinical, anthropometric, biochemical and nutritional assessments were conducted with 168 older adults, complemented by genotyping (rs9536314 and rs9527025) and detection of serum Klotho (ELISA). Results: Klotho levels and haplotypes did not associate with most classic risk factors for vascular events, in parallel to marker as C-reactive protein and homocysteine assessed as well. A positive association was only found between Klotho levels and previous occurrence of myocardial infarction, by both correlational $(p=0.006)$ and variance analyses $(p<0.001)$. Conclusion: Increased post-myocardial infarction serum Klotho is suggestive of an adaptive mechanism against pathological hypertrophy, and may represent a new biomarker for events at a specific territory.
\end{abstract}

Keywords: biomarker; cardiovascular event; vascular disorder; elderly; infarction; genotyping. 


\section{Introduction}

Globally, vascular diseases accounted for 17.5 million deaths in 2012. Coronary artery disease $(\mathrm{CAD})$ is the single most frequent cause of death worldwide, accounting for $12.8 \%$ (over 7 million) of all deaths whereas cerebrovascular events accounted for $11,9 \%$ of the same total (1). As the major finding associated with vascular events, atherosclerosis is a chronic/progressive, focal process with multifactorial etiology (genetic and lifestyle) which courses along with systemic disorders in hormonal and inflammatory mediators (86) that may have onset at early age but only clinically manifest later in life $(7,8)$. Atherosclerosis occurs in more than $50 \%$ of the westernized adult population worldwide $(10,12)$.

In this context, $\mathrm{CAD}$ is characterized by the narrowing of the walls of coronary arteries (stenosis) that leads to a reduction in blood flow to the heart muscle, mostly by accumulation of atheromatous plaques due to common risk factors are as diet-related disorders, smoking, family history and genetic factors, among others. As a possible outcome, myocardial infarctions (MI) damages the cardiac tissue, with diagnosis set by marked elevation of serum indicators (preferably troponin) accompanied by clinical aspects such as symptoms suggestive of ischemia, new Q waves on ECG, or evidence by imaging of loss of viable myocardium or ventricular contractility (15).

Regarding cerebrovascular diseases, 90\% result from lesions of the carotid arteries $(16,17)$ which account for cerebral vascular accidents (stroke) by the sudden closure or rupture of the arterial or venous vasculature brain (19). Regardless of the injury being hemorrhagic or ischemic (the latter defined as acute dysfunction in arterial territory (20)), brain damage can result from acute thrombotic event manifested by hemiplegia, aphasia or seizures (21). But no serum marker is available to date to specifically represent risk of vascular events at this territory.

The most important factors that are commonly assessed in clinical settings as suggestive of vascular events in general include circulating levels of homocysteine and Creactive protein (CRP), besides levels of lipoproteins and few other markers. Both homocysteine as CRP tend to show high concentrations in individuals at increased risk for the occurrence of vascular events (35). Although CRP predicts CAD-related events independently of other risk factors (36-38), its levels can also be transiently increased by 2 or 3 weeks due to 
large infection, trauma or extra-cardiac ischemic event (39), which can compromise a safe clinical evaluation based on this markers. It is also important to consider that circulating homocysteine is negatively correlated with intake of vitamins as B6, B12 and folate (40-43), being therefore nutritionally biased. Chronic renal failure may also interfere with breakdown of this biomarker, leading it to hyperhomocysteinemia (44). Thus, the low specificity of the markers considered so far leads to the need for new, reliable biomarkers of risk for vascular disorders (45), with studies in both clinical and experimental contexts taking place worldwide in search for candidate(s) less susceptible to interference by associated comorbidities or lifestyle. However, many molecular aspects in the development of atherosclerosis, CAD, MI and stroke are still unknown, and reveal an open field for studies to identify new factors of great value in the elaboration of clinical procedures for primary prevention or to assess subsequent stages.

In this sense, the Klotho protein can be a potential marker for vascular events. Studies have shown that the suppression of the Klotho gene in animal models causes extensive phenotypes similar to those of the aging phenotype, including atherosclerosis, ectopic calcification, infertility, skin atrophy and severe hypoglycemia (48), while its overexpression increases by 20 to $30 \%$ the total life span of guinea pigs (50). The human gene, located on chromosome 13, can undergo alternative splicing in its third exon, generating a secretable form (51). The Klotho gene bears six single nucleotide polymorphisms (SNPs) in exon 2 and flanking regions, all in perfect linkage disequilibrium and two resulting in substitutions with functional importance (F352V, rs9536314 and C370S, rs9527025), conforming the notorious FC and VS haplotypes $(52,53)$.

The main aim of this study was to simultaneously investigate the association of serum levels of C-reactive protein, homocysteine and Klotho with classical risk factors as well as with previous vascular events in a sample of elderly subjects, taking aspects as the usual intake of macronutrients and the common haplotypes of Klotho into consideration, among other covariates. 


\section{Materials and methods}

\subsection{Subjects and study design}

This report derives from cross-sectional analyses with data obtained from communitydwelling elderly women and men of the urban outskirts of the Brazilian Federal District, aged 60 or over and inscribed to undergo health screenings (medical, nutritional and/or pharmacological) to assess risk for vascular events in a cohort work know as Prognosis and Therapeutics in Geriatrics (ProTeGer) in Brasília, Brazil. Participation was voluntary and informed written consent was obtained from each subject. Data were collected from August 2011 to July 2014 during consultations in the Geriatric Service of the Catholic University Hospital.

For this analysis, the inclusion criteria were: to be aged $\geq 60$ years, to spontaneously seek for the service and to comply fulfilling the medical protocol. Exclusion criteria were: carriers of autoimmune disease, chronic or recurrent infections, neoplastic diseases, chronic renal disease (creatinine clearance $<25 \mathrm{~mL} / \mathrm{min} / 1.73 \mathrm{~m}^{2}$ ) and/or having used antiinflammatory drugs 30 days before clinical and biochemical tests.

This study was performed in accordance with the Declaration of Helsinki guidelines on good clinical practices and the Institutional ethical committee approved the study. No participants were receiving nutritional guidance at the time when laboratory and clinical data were obtained.

\subsection{Clinical procedures}

Each subject was required to undertake a medical protocol consisting of biochemistry, anthropometrical and clinical examination for admission in this study.

Medical evaluation investigated previous occurrence of vascular events such as CAD, MI and stroke based on clinical history reported by the patient and/or companion as well as by historical laboratory and/or image results supplied by the subjects. When based on reports, occurrence of any vascular event was computed only when independently declared in at least two medical visits. All queries by the clinical practitioners on prior events were conducted in a blinded manner to the information already on medical records. For our analysis, subjects were segregated as patients with or without previous vascular events.

Presence of comorbidities such as high blood pressure (HBP), dyslipidemia and type II diabetes mellitus, among others, was diagnosed based on the guidelines specific for each 
chronic condition, being also recorded whether drugs to control these conditions were in continued use. Practitioners of physical exercises were those exhibiting 30 minutes or over of exercises at any bout for at least four days a week (65), while the smoking habit was defined as consumption of $>100$ cigarettes over a lifetime (66).

Biochemical tests included determination of serum total cholesterol (TC) and fractions, triglycerides (TGL), glycemia, glycated hemoglobin, insulin, thyroid-stimulating hormone (TSH), CRP, and homocysteine. At admission, venous blood samples were drawn into EDTA-containing tube after a 12h-overnight fasting period. Laboratory tests were performed following routine clinical analysis with reagents from Boehringer Mannheim (Germany) and were processed in an AutoHumalyzer device (Human GMBH, Germany). Very low density lipoprotein cholesterol (VLDL-c) was determined by dividing TGL levels by 5 , whereas the Friedewald equation was used to yield low density lipoprotein cholesterol (LDL-c) by subtraction of both VLDL-c and high density lipoprotein cholesterol (HDL-c) from TC. Cases were evaluated as negative or positive to assemble categorical variables for metabolic disorders. Lipid categorization was carried out according to NCEP ATP III (68), with each volunteer identified as a carrier (or not) of mixed hyperlipemia (TC $\geq 200 \mathrm{mg} / \mathrm{dl}$, LDL-c $\geq 130 \mathrm{mg} / \mathrm{dl}$ and/or TGL $\geq 150 \mathrm{mg} / \mathrm{dl}$ ). Current use of antilipidemic drugs was considered in the definition of hyperlipidemia. Type 2 diabetes was defined according to reference values established by the American Diabetes Association (fasting glycemia $\geq 126$ $\mathrm{mg} / \mathrm{dl}$ ) (69) or current use of oral hypoglycemic drugs or insulin. Systolic and diastolic arterial blood pressure were measured as recommended by the VI Brazilian Guidelines for Arterial Hypertension (70). Patients with systolic arterial blood pressure $\geq 140 \mathrm{mmHg}$ and/or diastolic arterial blood pressure $\geq 90 \mathrm{mmHg}$ were classified as hypertensive, as well as those regularly taking antihypertensive drugs. The HOMA index is the calculated based on the ratio of the product of fasting insulin (mU/L) and fasting glucose (mmol/L) by 22.5 (71).

\subsection{Dietary evaluation}

The present study evaluated the usual consumption of macronutrients by the elderly women and men. For that, a non-consecutive three-day dietary record was completed, including one weekend day. To fill out the forms correctly, each patient received information from trained dieticians on the number and sizes of food portions. To ensure completion of the dietary record, the nutrition staff provided either personal or telephone assistance. 
Seven to ten days after being distributed, the forms were returned by patients during their first, subsequent office visit, scheduled to check the accuracy of the records and complete lacking information. Analysis of nutrient composition was carried out with Diet Pro software, version 5i (A.S. Sistemas, Brazil), adjusted for all available databases and complemented with a chemical composition table for Brazilian foods (72). Subjects whose records indicated use of macronutrient-containing supplementary stuffs were excluded from analyses.

After entry of dietary data, absolute intakes (mg) of carbohydrates, protein and lipids were individually calculated. Absolute intakes were converted into relative calories from these macronutrients in relation to total dietary intake, also in calories, rendering variables referred to as dietary intakes of carbohydrates (DIC), of lipids (DIL) and of proteins (DIP). Total energy intake (TEI) and the macronutrient assessments were expressed as the mean daily intake based on the 3-day dietary records.

To increase the reliability of data collected, the version in Brazilian Portuguese of the Mini-Mental State Examination (MMSE) (73) was applied to each patient, and exclusion from analyses was defined according to the educational level: $<13$ for illiterate individuals $<17$ for individuals with 1-7 years of schooling, and $<25$ for individuals with eight or more years of formal education (74).

Waist circumference was measured at the midpoint between the last rib and the iliac crest at the time of the individual's expiration (67).

\subsection{Klotho Genotyping}

Ten milliliters of blood were collected by venipuncture into tubes containing heparin, with plasma obtained by refrigerated centrifugation $\left(4^{\circ} \mathrm{C}\right)$ of $5 \mathrm{ml}$ at $1,000 \mathrm{~g}$ for $15 \mathrm{~min}$.

Plasma was aliquoted and immediately frozen at $-20^{\circ} \mathrm{C}$ until testing. DNA extraction used $5 \mathrm{ml}$ of blood by the salting out method (44). The determination of FC and VS haplotypes of the Klotho gene was performed as described by Arking and colleagues (52), with modifications. Briefly, both polymorphic sites F352V (T/G; rs9536314) and C370S (G/C; rs9527025) were amplified in the same DNA segment by polymerase chain reaction (PCR), with forward 5 'aggctcatgccaaagtctgg 3' and reverse 5 'gtttccatgatgaacttttgagg 3' primers. Amplification conditions consisted of hot start at $80^{\circ} \mathrm{C}$ for $1 \mathrm{~min}$, followed by initial denaturation at $94{ }^{\circ} \mathrm{C}$ for $2 \mathrm{~min}$ and 36 cycles at $94{ }^{\circ} \mathrm{C}$ for $40 \mathrm{~s}$, annealing at $60^{\circ} \mathrm{C}$ for $45 \mathrm{~s}$ and 
extension at $72{ }^{\circ} \mathrm{C}$ for $50 \mathrm{~s}$, and completed at $72{ }^{\circ} \mathrm{C}$ for $5 \mathrm{~min}$. Amplification of the $505 \mathrm{pb}$ products was confirmed by eletrophoresis in $1.6 \%$ agarose gels. Having primer exhaustion visually verified, identification of the polymorphic points was conducted by direct, automatized sequencing of amplification products in a 3130 DNA Analyzer system (Foster City, CA, USA), using manufacturer's reagents and procedures (Applied Biosystems). Sequencing reactions were performed using both forward and reverse primer for the PCR step. Sequencing was recorded as successful if high quality sequence was obtained in at least one direction.

\subsection{Serum detection of the Klotho protein}

The Klotho protein concentration in serum is determined by ELISA (Enzyme-linked Immunosorbent Assay) using specific kit produced by the BlueGene ${ }^{\circledR}$ Biotech company (Shangai, China), according to the manufacturer's instructions.

\subsection{Statistical analysis}

To start, the Student's t test was used to test the influence of Klotho haplotypes on continuous anthropometric, clinical and biochemical variables. Then, to evaluate the occurrence and strength of the association of circulating levels of Klotho and of other classic biomarkers (C-reactive protein and homocysteine) with prior vascular events, correlation coefficients were obtained between the serum biomarkers investigated and the continuous and categorical anthropometric, clinical and biochemical variables of potential confounding effect in the main model. For that, close-to-normal distribution of all continuous variables was assessed using the Kolmogorov-Smirnov test. The association between continuous variables was evaluated using the Pearson's correlation test, whereas the involvement of a least one categorical variable in the model was dealt using the Spearman's counterpart, with men and women represented by 1 or 2 , and absence or presence of a feature represented by 0 or 1 , respectively. Whenever an interaction was noticed, association of the biomarkers with the vascular events was tested by means of partial correlation analyses run using adjustment for the confounding variable(s) or condition(s). Also, raw concentrations of each biomarker were tested across individuals that exhibited or not acute MI prior to the study onset using the Student $\mathrm{t}$ test. When results show significant differences, the effect sizes $(d)$ and respective confidence intervals (95\% CI) were presented. Linear multivariate regression analysis, 
stepwise method, was performed to assess at which extent serum concentrations of the biomarkers explain the variability in occurrence of the vascular events.

All analyses were performed with the Statistical Package for the Social Sciences (SPSS) for Windows (version 17.0). For this study, a $p$-value (two-tailed) was rendered significant following the Bonferroni's principle of correction for multiple comparisons whenever a given trait is tested across $k$ independent variables $(k=10$ tests $\therefore \alpha \leq 0.005)$.

\section{Results}

After clinical-laboratory and dietary assessment and verification of the inclusion and exclusion criteria, the eligible sample for analyses was composed of 168 elderly patients with mean age of 73.1 years. For the F352V polymorphism, $138(82.1 \%)$ of the subjects were FF homozygotes, whereas $27(16.1 \%)$ had the FV genotype and $3(1.8 \%)$ had the VV genotype. The exact same proportions were found for CC, CS and SS genotypes, with firm correspondence between $\mathrm{F}$ and $\mathrm{C}$ carriage as well as between $\mathrm{V}$ and $\mathrm{S}$ presence in each individual genotype, what is consistent with perfect linkage disequilibrium across these two SNPs in our sample. This finding is highly consistent with the assumption advocated by Arking and coworkers to whom identification of the F352V variation per se can be used as surrogate for the determination of the whole haplotype for epidemiological purposes (75).

Table 1 presents the results of an inferential analysis of results, which investigated the association of Klotho haplotype with the leading clinical-laboratory variables determined in the sample. In clinical terms, the sample characterization revealed that subjects had relatively low proportion of previous vascular events, but with significant prevalence of metabolic disorders compatible with a profile eligible for primary prevention. The analysis showed no association of haplotypes with any of the basic variables. Also, there were no differences in the prevalence of prior CAD, stroke and AMI cases between the haplotypic groups.

The possibility of association of clinical-laboratory and dietary variables of the sample with circulating Klotho levels was verified using correlation tests (Table 2), where traditional serum markers for vascular events (CRP and homocysteine) were considered. In this context, serum CRP and homocysteine levels were significantly influenced by gender, with the average level of the former $87 \%$ higher among women $[p=0.012 ; d=0.23(0.1 ; 0.4)]$. whereas the latter at $34 \%$ among men $[p=0.020 ; d=-0.25(-0.4 ;-0.1)]$. In addition, sedentary individuals exhibited mean serum CRP level 75\% higher $[p=0.044 ; d=0.23(0.1 ; 0.4)]$ than 
values shown by physically active individuals. Apart from these associations, our correlation analyses revealed no other significant association between the three serum biomarkers and any of the clinical, biochemistry and dietary features investigated. Therefore, Klotho levels do not seem to be influenced by demographic aspects, lifestyle or comorbidities presented by patients in a context compatible with primary care settings. Accordingly, macronutrients intake was not significantly correlated with any of the serum markers considered.

Then, correlation analyses were performed to investigate the association of the CRP, homocysteine and Klotho biomarkers with occurrence of previous vascular events (CAD, MI and stroke) at baseline (Table 3). These analyses were controlled for confounding factors (gender and physical inactivity) previously associated with some biomarkers, and the main result consisted of a positive association between circulating Klotho levels and previous occurrence of acute myocardial infarction. When comparing the serum levels of CRP, homocysteine and Klotho among subjects, it was observed that Klotho was the only marker to display different levels [72\% higher among affected by MI; $p<0.001 ; \mathrm{d}=1.6(0.9-2.6)$ ] according to previous history of acute myocardial infarction (Figure 1).

By analyzing the multiplicity of classic clinical, anthropometric and biochemical risk factor for vascular events along with the circulating mediators investigated herein, stepwise multivariate regression showed that levels of Klotho were the single most predictive variable in the model $\left(\mathrm{R}^{2}=0.086\right)$, and accounted for $29,3 \%$ of the variance in occurrence of acute myocardial infarction in the sample.

\section{Discussion}

Our study suggests that serum Klotho can be an independent marker for post-event MI among elderly individuals, with possible implication for secondary prevention, given the enhanced levels of the mediator among the affected outpatients. To our knowledge, this is the first report about this association. However, serum Klotho levels have been associated with different vascular risk factors in humans such as atherosclerosis, oxidative stress and endothelial dysfunction $(48,50,63,76)$. Most findings in the literature suggest a role for augmented serum Klotho in susceptibility to vascular, metabolic-bourne disorders. Intriguingly, our analyses on qualitatively and quantitatively portrayed metabolic traits (pressoric, lipemic, glycemic) of older adults across Klotho haplotypes or levels showed no 
significant association. None could either be devised when considering classic anthropometric measures, life style features and health care practices. In our setting, the evidence lead us to suggest that Klotho does not relate to (and may not be an actual player in) the development of vascular disorders and events. Instead, we hypothesize that Klotho may be a so far unnoticed pathophysiological element linked to the cardiac post-myocardial infarction state.

It is known that ventricular dilation takes place at the acute phase (ventriculomegaly) of MI, as well as late cavitary dilation can occur due to eccentric hypertrophy $(77,78)$. These are adaptation processes in which the heart tends to assume a spherical shape due to the redistribution of forces for maintaining ventricular function as opposed to increased parietal stress (greater parietal tension in diastole than in systole) (79-81). Hypertrophied hearts in animal models show increased expression of TRPC6 channels (transient receptor potential canonical 6), whose expression is regulated by different tensions and intensities. Soluble Klotho is known for inhibiting TRPC6 cardiac channels, and thus for protecting the myocardium against excessive/pathological remodeling (82). Thus, it is plausible that high Klotho levels in post-infarction appear as an adaptation mechanism to this event in humans, supporting the finding of our study.

In favor of a rationale that supports compensatory properties of Klotho after MI, studies show that adenovirus-mediated delivery of the gene into animal model ameliorated vascular endothelial dysfunction and prevented myocardial medial hypertrophy $(76,83)$. Yet, studies that found association of serum Klotho levels in infarcted humans have not been found in literature.

Beyond the functions already mentioned, Klotho can also act on the maturation of adipocytes and on glucose metabolism. Studies have shown that Klotho knockout rats are resistant to obesity even when submitted to a high fat diet $(84,85)$, revealing also a clear synergy between the soluble marker and diet. In order to control these potential covariates, the total caloric intake and the proportional intake of macronutrients acquired by the sample from usual diet were investigated in our study. However, our results indicate no significant interaction between dietary profile and serum Klotho levels. Thus, the possibility that intake pattern is responsible for possible diet-related effect variations of the mediators investigated was ruled out.

Although patients with major infarction-related myocardial remodeling show progressive worsening of cardiac function, there is still no reliable marker for such process, and slowing or reversing remodeling remains a challenge in clinical care of post-AMI 
subjects. However, few are the studies in this field, and controversy (if any) may arise from confounding factors not adequately investigated or controlled. In this regard, our work tends to offer a contribution by assuring that circulating Klotho did not vary under the influence of classic risk factors for vascular events (eg.: glycemic and lipemic profiles), healthcare measures or demographic aspects as other biomarkers currently used in clinical practice (CRP and homocysteine) usually vary. We were unable to rule out from our analysis subjects who consumed blood pressure-, glucose- or lipid-lowering drugs (> 85\% of the sample). But our analyses proved that these therapies do not to alter any of the biomarkers investigated. However, there are limitations in our study that are worth mentioning. Initially, this is a crosssectional study, and an influence by the time elapsed since myocardial infarction cannot be discarded. Also, the overall number of subjects was limited to detect small differences in the associations investigated. For instance, our results did not show significant MI-related differences of CRP levels, with post hoc power analysis of our own showing that only a sample of 1116 individuals would suffice to provide power $[d=0.20(-0.19 ; 0.59)]$ to detect small differences on this variable. But on what concerns Klotho levels, it is outstanding that a reasonable effect size was reached in correlational analysis $[d=0.22(0.1-0.4)]$ for our sample size of 168 subjects. Therefore, the results of our study could be interpreted with fairly adequate power to detect meaningful differences.

\section{Conclusion}

Our results show that serum Klotho is higher in individuals with clinical history of myocardial infarction, but not with history of coronary artery disease or stroke. Classic risk factors for vascular diseases were not associated either with serum Klotho or with its main genetic variations. It is suggested herein that the augmented post-infarction Klotho may reflect a compensatory mechanism to prevent pathological myocardial hypertrophy. However, further studies with the appropriate, prospective design are needed to evaluate the pathophysiological mechanisms of serum Klotho fluctuation in post-event settings. 
Acknowledgments: The research was supported with grants \#471016/2011-0 (CNPq) and \#193.000.032-2012 (FAPDF), with a stipend to W. Machado-Silva (CAPES) and a fellowship for productivity in research to O.T. Nóbrega (CNPq).

Conflict of interest: No potential conflicts of interest exist.

\section{Author contributions:}

R.S. Paula and W. Machado-Silva: executed the clinical anthropometric and pharmacological assessments, respectively.

L. Gomes and C.F. Moraes: executed the medical component of the study.

V.C. Souza, A.C. Daros and B.R.S. Almeida: participated in the laboratory assessments of Klotho genotypes and levels.

C.J. Brito, C. Córdova and O.T. Nóbrega: designed and coordinated the study.

R.S. Paula and O.T. Nóbrega: analyzed and interpreted the results; participated in the preparation of the original manuscript. 


\section{References}

[1] World Health Organization. The top 10 causes of death. Updated May 2014 ed. http://www.who.int/mediacentre/factsheets/fs310/en/: WHO; 2014.

[2] Pankow JS, Folsom AR, Cushman M, Borecki IB, Hopkins PN, Eckfeldt JH, et al. Familial and genetic determinants of systemic markers of inflammation: the NHLBI family heart study. Atherosclerosis. 2001;154:681-9.

[3] Kannel WB, Wilson PW. An update on coronary risk factors. The Medical clinics of North America. 1995;79:951-71.

[4] Tracy RE, Newman WP, 3rd, Wattigney WA, Berenson GS. Risk factors and atherosclerosis in youth autopsy findings of the Bogalusa Heart Study. The American journal of the medical sciences. 1995;310 Suppl 1:S37-41.

[5] Mallika V, Goswami B, Rajappa M. Atherosclerosis pathophysiology and the role of novel risk factors: a clinicobiochemical perspective. Angiology. 2007;58:513-22.

[6] Ross R. Atherosclerosis--an inflammatory disease. The New England journal of medicine. 1999;340:115-26.

[7] Thygesen K, Alpert JS, Jaffe AS, Simoons ML, Chaitman BR, White HD, et al. Third universal definition of myocardial infarction. European heart journal. 2012;33:2551-67.

[8] Bonamigo TL, Lucas ML. Análise crítica das indicações e resultados do tratamento cirúrgico da doenca carotídea. J Vasc Bras. 2007;6:366-77.

[9] Illuminati G, Calio FG, Papaspyropoulos V, Montesano G, D'Urso A. Revascularization of the internal carotid artery for isolated, stenotic, and symptomatic kinking. Archives of surgery. 2003;138:192-7.

[10] Giroud M, Lemesle M, Madinier G, Manceau E, Osseby GV, Dumas R. Stroke in children under 16 years of age. Clinical and etiological difference with adults. Acta neurologica Scandinavica. 1997;96:401-6.

[11] Kenet G, Sadetzki S, Murad H, Martinowitz U, Rosenberg N, Gitel S, et al. Factor V Leiden and antiphospholipid antibodies are significant risk factors for ischemic stroke in children. Stroke; a journal of cerebral circulation. 2000;31:1283-8.

[12] Lanthier S, Carmant L, David M, Larbrisseau A, de Veber G. Stroke in children: the coexistence of multiple risk factors predicts poor outcome. Neurology. 2000;54:371-8.

[13] Wald DS, Law M, Morris JK. Homocysteine and cardiovascular disease: evidence on causality from a meta-analysis. Bmj. 2002;325:1202.

[14] Francisco G, Hernandez C, Simo R. Serum markers of vascular inflammation in dyslipemia. Clinica chimica acta; international journal of clinical chemistry. 2006;369:1-16.

[15] Grundy SM, Cleeman JI, Daniels SR, Donato KA, Eckel RH, Franklin BA, et al. Diagnosis and management of the metabolic syndrome: an American Heart Association/National Heart, Lung, and Blood Institute Scientific Statement. Circulation. 2005;112:2735-52.

[16] National Cholesterol Education Program Expert Panel on Detection E, Treatment of High Blood Cholesterol in A. Third Report of the National Cholesterol Education Program (NCEP) Expert Panel on Detection, Evaluation, and Treatment of High Blood Cholesterol in Adults (Adult Treatment Panel III) final report. Circulation. 2002;106:3143-421.

[17] Wilson PW, D'Agostino RB, Levy D, Belanger AM, Silbershatz H, Kannel WB. Prediction of coronary heart disease using risk factor categories. Circulation. 1998;97:183747.

[18] Boushey CJ, Beresford SA, Omenn GS, Motulsky AG. A quantitative assessment of plasma homocysteine as a risk factor for vascular disease. Probable benefits of increasing folic acid intakes. Jama. 1995;274:1049-57. 
[19] Graham IM, Daly LE, Refsum HM, Robinson K, Brattstrom LE, Ueland PM, et al. Plasma homocysteine as a risk factor for vascular disease. The European Concerted Action Project. Jama. 1997;277:1775-81.

[20] Kang SS, Zhou J, Wong PW, Kowalisyn J, Strokosch G. Intermediate homocysteinemia: a thermolabile variant of methylenetetrahydrofolate reductase. American journal of human genetics. 1988;43:414-21.

[21] Selhub J, Jacques PF, Wilson PW, Rush D, Rosenberg IH. Vitamin status and intake as primary determinants of homocysteinemia in an elderly population. Jama. 1993;270:2693-8.

[22] Diniz-Santos DR, Andrade GCFd. A homocisteína como fator de risco para aterosclerose. R Ci méd biol. 2005;4:158-66.

[23] Vlachopoulos C, Xaplanteris P, Aboyans V, Brodmann M, Cifkova R, Cosentino F, et al. The role of vascular biomarkers for primary and secondary prevention. A position paper from the European Society of Cardiology Working Group on peripheral circulation: Endorsed by the Association for Research into Arterial Structure and Physiology (ARTERY) Society. Atherosclerosis. 2015;241:507-32.

[24] Kuro-o M, Matsumura Y, Aizawa H, Kawaguchi H, Suga T, Utsugi T, et al. Mutation of the mouse klotho gene leads to a syndrome resembling ageing. Nature. 1997;390:45-51.

[25] Kurosu H, Yamamoto M, Clark JD, Pastor JV, Nandi A, Gurnani P, et al. Suppression of aging in mice by the hormone Klotho. Science. 2005;309:1829-33.

[26] Matsumura Y, Aizawa H, Shiraki-Iida T, Nagai R, Kuro-o M, Nabeshima Y. Identification of the human klotho gene and its two transcripts encoding membrane and secreted klotho protein. Biochemical and biophysical research communications. 1998;242:626-30.

[27] Arking DE, Becker DM, Yanek LR, Fallin D, Judge DP, Moy TF, et al. KLOTHO allele status and the risk of early-onset occult coronary artery disease. Am J Hum Genet. 2003;72:1154-61.

[28] Rhee EJ, Oh KW, Lee WY, Kim SY, Jung CH, Kim BJ, et al. The differential effects of age on the association of KLOTHO gene polymorphisms with coronary artery disease. Metabolism: clinical and experimental. 2006;55:1344-51.

[29] Physical Activity Guidelines Advisory Committee report, 2008. To the Secretary of Health and Human Services. Part A: executive summary. Nutrition reviews. 2009;67:114-20.

[30] Backinger CL, Fagan P, O'Connell ME, Grana R, Lawrence D, Bishop JA, et al. Use of other tobacco products among U.S. adult cigarette smokers: prevalence, trends and correlates. Addictive behaviors. 2008;33:472-89.

[31] Expert Panel on Detection E, Treatment of High Blood Cholesterol in A. Executive Summary of The Third Report of The National Cholesterol Education Program (NCEP) Expert Panel on Detection, Evaluation, And Treatment of High Blood Cholesterol In Adults (Adult Treatment Panel III). Jama. 2001;285:2486-97.

[32] American Diabetes A. Standards of medical care in diabetes. Diabetes care. 2005;28 Suppl 1:S4-S36.

[33] Sociedade Brasileira de C, Sociedade Brasileira de H, Sociedade Brasileira de N. [VI Brazilian Guidelines on Hypertension]. Arq Bras Cardiol. 2010;95:1-51.

[34] Matthews DR, Hosker JP, Rudenski AS, Naylor BA, Treacher DF, Turner RC. Homeostasis model assessment: insulin resistance and beta-cell function from fasting plasma glucose and insulin concentrations in man. Diabetologia. 1985;28:412-9.

[35] Philippi ST. Tabela de composição de alimentos: suporte para decisão nutricional. 2 nd ed. São Paulo- Brasil: Coronário; 2002. 
[36] Folstein MF, Folstein SE, McHugh PR. "Mini-mental state". A practical method for grading the cognitive state of patients for the clinician. Journal of psychiatric research. 1975;12:189-98.

[37] Castro-Costa E, Fuzikawa C, Uchoa E, Firmo JO, Lima-Costa MF. Norms for the MiniMental State Examination: adjustment of the cut-off point in population-based studies (evidences from the Bambui health aging study). Arq Neuropsiquiatr. 2008;66:524-8.

[38] Lohmann TG, Roche AF, Martorell R. Anthropometric Standardization Reference Manual: Human Kinetics Books, Champaign, Ill.; 1988.

[39] Arking DE, Krebsova A, Macek M, Sr., Macek M, Jr., Arking A, Mian IS, et al. Association of human aging with a functional variant of klotho. Proceedings of the National Academy of Sciences of the United States of America. 2002;99:856-61.

[40] Saito Y, Nakamura T, Ohyama Y, Suzuki T, Iida A, Shiraki-Iida T, et al. In vivo klotho gene delivery protects against endothelial dysfunction in multiple risk factor syndrome. Biochemical and biophysical research communications. 2000;276:767-72.

[41] Saito Y, Yamagishi T, Nakamura T, Ohyama Y, Aizawa H, Suga T, et al. Klotho protein protects against endothelial dysfunction. Biochemical and biophysical research communications. 1998;248:324-9.

[42] Anversa P, Loud AV, Levicky V, Guideri G. Left ventricular failure induced by myocardial infarction. II. Tissue morphometry. The American journal of physiology. 1985;248:H883-9.

[43] Anversa P, Sonnenblick EH. Ischemic cardiomyopathy: pathophysiologic mechanisms. Progress in cardiovascular diseases. 1990;33:49-70.

[44] Cohn JN, Ferrari R, Sharpe N. Cardiac remodeling--concepts and clinical implications: a consensus paper from an international forum on cardiac remodeling. Behalf of an International Forum on Cardiac Remodeling. Journal of the American College of Cardiology. 2000;35:569-82.

[45] Pfeffer MA, Braunwald E. Ventricular remodeling after myocardial infarction. Experimental observations and clinical implications. Circulation. 1990;81:1161-72.

[46] Zornoff LA, Spadaro J. [Ventricular remodeling after acute myocardial infarction. Concepts, pathophysiology and therapeutic approach]. Arquivos brasileiros de cardiologia. 1997;68:453-60.

[47] Frey N, Katus HA, Olson EN, Hill JA. Hypertrophy of the heart: a new therapeutic target? Circulation. 2004;109:1580-9.

[48] Yang J, Matsukawa N, Rakugi H, Imai M, Kida I, Nagai M, et al. Upregulation of cAMP is a new functional signal pathway of Klotho in endothelial cells. Biochemical and biophysical research communications. 2003;301:424-9.

[49] Ohnishi M, Kato S, Akiyoshi J, Atfi A, Razzaque MS. Dietary and genetic evidence for enhancing glucose metabolism and reducing obesity by inhibiting klotho functions. FASEB journal : official publication of the Federation of American Societies for Experimental Biology. 2011;25:2031-9.

[50] Razzaque MS. The role of Klotho in energy metabolism. Nature reviews Endocrinology. 2012;8:579-87. 
Table 1. Anthropometric,clinical and metabolic variables of the sample.

\begin{tabular}{|c|c|c|c|c|}
\hline \multirow[b]{2}{*}{ Variables } & \multicolumn{3}{|c|}{ Groups } & \multirow[b]{2}{*}{$p$} \\
\hline & $\begin{array}{c}\text { All } \\
(\mathrm{n}=168)\end{array}$ & $\begin{array}{c}\mathrm{FC} / \mathrm{FC} \\
(\mathrm{n}=138)\end{array}$ & $\begin{array}{l}\text { /VS } \\
(\mathrm{n}=30)\end{array}$ & \\
\hline Male, \% & 39.9 & 37.7 & 50.0 & 0.212 \\
\hline Age, years & $73.1 \pm 9.0$ & $73.0 \pm 8.7$ & $73.7 \pm 10.1$ & 0.677 \\
\hline $\mathrm{WC}, \mathrm{cm}$ & $97.4 \pm 11.5$ & $98.0 \pm 11.8$ & $95.2 \pm 9.9$ & 0.204 \\
\hline Glucose level, mg.dl ${ }^{-1}$ & $103.2 \pm 27.7$ & $104.4 \pm 29.9$ & $98.2 \pm 13.2$ & 0.082 \\
\hline $\mathrm{HbA} 1 \mathrm{c}, \%$ & $5.9 \pm 1.0$ & $5.9 \pm 1.1$ & $5.7 \pm 0.6$ & 0.280 \\
\hline Insulin, mUI/mL & $9.3 \pm 10.0$ & $9.7 \pm 10.8$ & $7.3 \pm 4.9$ & 0.230 \\
\hline HOMA index & $2.6 \pm 3.8$ & $2.8 \pm 4.1$ & $1.8 \pm 1.2$ & 0.163 \\
\hline $\mathrm{DM} 2^{\S}, \%$ & 22.6 & 26.1 & 6.7 & 0.021 \\
\hline Total cholesterol, mg.dl ${ }^{-1}$ & $193.4 \pm 39.9$ & $192.3 \pm 36.2$ & $198.8 \pm 50.1$ & 0.404 \\
\hline LDL-c, mg. $\mathrm{dl}^{-1}$ & $115.3 \pm 33.7$ & $114.4 \pm 33.1$ & $119.6 \pm 37.0$ & 0.448 \\
\hline Triglycerides, mg. $\mathrm{dl}^{-1}$ & $141.2 \pm 64.7$ & $143.3 \pm 62.1$ & $131.6 \pm 75.8$ & 0.370 \\
\hline Hyperlipemia $^{\S}, \%$ & 51.8 & 50.7 & 56.7 & 0.438 \\
\hline HDL-c, mg. $\mathrm{dl}^{-1}$ & $48.1 \pm 10.9$ & $47.5 \pm 10.6$ & $50.8 \pm 12.2$ & 0.135 \\
\hline $\mathrm{SBP}, \mathrm{mm} \mathrm{Hg}$ & $134.8 \pm 19.5$ & $134.8 \pm 19.5$ & $134.5 \pm 19.8$ & 0.927 \\
\hline $\mathrm{DBP}, \mathrm{mm} \mathrm{Hg}$ & $80.6 \pm 11.1$ & $80.6 \pm 11.1$ & $80.8 \pm 11.8$ & 0.918 \\
\hline $\mathrm{SAH}^{\S}, \%$ & 77.4 & 78.3 & 73.3 & 0.559 \\
\hline CRP, mg. $\cdot \mathrm{dl}^{-1}$ & $3.5 \pm 5.6$ & $3.7 \pm 5.8$ & $2.6 \pm 4.3$ & 0.339 \\
\hline TSH, mIU. $1^{-1}$ & $2.5 \pm 2.2$ & $2.6 \pm 2.3$ & $2.2 \pm 1.6$ & 0.294 \\
\hline Homocysteine, $\mu$ mol..$^{-1}$ & $12.8 \pm 8.8$ & $12.5 \pm 8.7$ & $14.0 \pm 9.1$ & 0.413 \\
\hline Previous stroke ${ }^{\S}, \%$ & 9.5 & 10.9 & 3.3 & 0.202 \\
\hline Previous $\mathrm{AMI}^{\S}, \%$ & 4.2 & 4.3 & 3.3 & 0.801 \\
\hline Previous $\mathrm{CAD}^{\S}, \%$ & 1.8 & 2.2 & - & 0.415 \\
\hline Sedentary $^{\S}, \%$ & 60.7 & 61.6 & 56.7 & 0.616 \\
\hline Smoker $^{\S}, \%$ & 37.3 & 36.5 & 41.4 & 0.621 \\
\hline klotho, ng. $\mathrm{ml}^{-1}$ & $1.2 \pm 0.6$ & $1.2 \pm 0.6$ & $1.2 \pm 0.8$ & 0.743 \\
\hline
\end{tabular}

Data are expressed as average \pm standard deviation for continuous parameters or relative frequencies for categorical features.The Student's t test or the chi-square ${ }^{\S}$ test were used. $\mathrm{WC}=$ waist circumference; HbA1c = glycated hemoglobin A1c; HOMA = Homeostatic model assessment; DM2 = type 2 diabetes mellitus; LDL-c = low density lipoprotein cholesterol; HDL-c = high density lipoprotein cholesterol, $\mathrm{SBP}=$ systolic blood pressure; $\mathrm{DBP}=$ diastolic blood pressure; $\mathrm{SAH}=$ systemic arterial hypertension; $\mathrm{CRP}=\mathrm{C}$-reactive protein; $\mathrm{TSH}=$ thyroid-stimulating hormone; $\mathrm{AMI}$ $=$ acute myocardial infarction; $\mathrm{CAD}=$ coronary artery disease. Significance threshold set at $p \leq 0.002$ according to the Bonferroni convention. 
Table 2. Correlation analyses of raw serum levels of C-reactive protein, homocysteine and klotho across clinical, biochemical and healthcare features of the 168 older subjects at admission.

\begin{tabular}{|c|c|c|c|c|c|c|}
\hline & Age & $\operatorname{Sex}^{\S}$ & SBP & DBP & $\mathrm{SAH}^{\S}$ & $\alpha \mathrm{SAH}^{\S}$ \\
\hline CRP & $.09 ; .242$ & $.23 ; .002^{\#}$ & $-.07 ; .399$ & $-.10 ; .195$ & $.09 ; .268$ & $.09 ; .238$ \\
\hline Homocysteine & $.18 ; .022$ & $-.25 ; .001^{\mathfrak{E}}$ & $-.10 ; .203$ & $-.18 ; .022$ & $.05 ; .544$ & $.07 ; .373$ \\
\hline \multirow[t]{2}{*}{ Klotho } & $.11 ; .178$ & $.06 ; .424$ & $-.18 ; .025$ & $-.16 ; .041$ & $-.06 ; .473$ & $-.05 ; .538$ \\
\hline & WC & Sedentary ${ }^{\S}$ & $\mathrm{HbA1c}$ & HOMA & $\mathrm{DM} 2^{\S}$ & $\alpha \mathrm{DM} 2^{\S}$ \\
\hline CRP & $.08 ; .289$ & $.23 ; .002^{¥}$ & $-.07 ; .400$ & $.20 ; .010$ & $.05 ; .492$ & $.01 ; .873$ \\
\hline Homocysteine & $.02 ; .791$ & $.11 ; .165$ & $-.02 ; .764$ & $.01 ; .933$ & $.09 ; .233$ & $.01 ; .884$ \\
\hline \multirow[t]{2}{*}{ Klotho } & $-.05 ; .524$ & $.07 ; .375$ & $-.07 ; .353$ & $-.07 ; .404$ & $-.01 ; .898$ & $.03 ; .660$ \\
\hline & $\mathrm{TC}$ & LDL-c & TGL & hyperlipemia & HDL-c & alipemics $^{\S}$ \\
\hline CRP & $.03 ; .722$ & $-.06 ; .433$ & $-.01 ; .887$ & $.03 ; .686$ & $-.03 ; .687$ & $-.01 ; .968$ \\
\hline Homocysteine & $-.12 ; .119$ & $-.06 ; .474$ & $-.03 ; .672$ & $-.06 ; .476$ & $-.09 ; .233$ & $.06 ; .405$ \\
\hline \multirow[t]{2}{*}{ Klotho } & $-.18 ; .021$ & $-.10 ; .204$ & $-.05 ; .537$ & $-.01 ; .935$ & $-.06 ; .444$ & $-.02 ; .802$ \\
\hline & Drinker ${ }^{\S}$ & Smoker ${ }^{\S}$ & DIC & DIL & DIP & TEI \\
\hline CRP & $.12 ; .108$ & $.13 ; .098$ & $-.05 ; .610$ & $-.04 ; .697$ & $.18 ; .050$ & $-.04 ; .673$ \\
\hline Homocysteine & $.17 ; .025$ & $.12 ; .134$ & $-.13 ; .161$ & $.13 ; .179$ & $.07 ; .484$ & $.01 ; .924$ \\
\hline Klotho & $.02 ; .790$ & $.14 ; .086$ & $.10 ; .277$ & $-.19 ; .045$ & $.12 ; .193$ & $-.20 ; .031$ \\
\hline
\end{tabular}

The Pearson's or the Spearman's ${ }^{\S}$ correlation test were used. For the latter, presence or absence of a feature was represented by 1 or 0 , respectively. Data are expressed in correlation index and significance level $(r ; p) . \alpha=$ use of therapeutic drugs for the condition; $\mathrm{WC}=$ waist circumference; $\mathrm{SBP}=$ systolic blood pressure; $\mathrm{DBP}=$ diastolic blood pressure; $\mathrm{TC}=$ total cholesterol; HDL-c $=$ high density lipoprotein cholesterol; HOMA $=$ Homeostatic model assessment; HbA1c $=$ glycated hemoglobinA1c; $\mathrm{SAH}=$ systemic arterial hypertension; DM2 = type 2 diabetes mellitus; DIC = dietary intake of carbohydrates; DIL = dietary intake of lipids; DIP = dietary intake of proteins; TEI = total energy intake. Significance threshold set at $P \leq 0.002$ according to the Bonferroni convention. Superscript \#, $£$ and $¥$ represent effect sizes $(d)$ and $95 \%$ confidence intervals (in parenthesis) of 0.23 $(0.1 ; 0.4),-0.25(-0.4 ;-0.1)$ and $0.23(0.1 ; 0.4)$, respectively. 
Table 3. Correlation analyses of raw serum levels of C-reactive protein, homocysteine and klotho across carriers and non-carriers of vascular events developed prior to admission in the study.

\begin{tabular}{lccr}
\hline \multicolumn{4}{c}{ Vascular events } \\
\hline & Stroke & AMI & \multicolumn{1}{c}{ CAD } \\
\hline CRP $^{\dagger, t}$ & $.14 ; .066$ & $.04 ; .615$ & $-.06 ; .465$ \\
homocysteine $^{\dagger}$ & $.12 ; .124$ & $.01 ; .902$ & $.01 ; .911$ \\
Klotho & $.07 ; .381$ & $.22 ; .006^{\#}$ & $-.13 ; .100$ \\
\hline
\end{tabular}

The Spearman's or the Partial (for adjustments) correlation test was used, adjusted for ${ }^{\dagger}$ sex and/or tphysical activity when appropriate. Presence or absence of a feature was represented by 1 or 0 , respectively. Data are expressed in correlation index and significance level $(r ; p)$. AMI $=$ acute myocardial infarction; $\mathrm{CAD}=$ coronary artery disease. Significance threshold set at $P \leq 0.016$ according to the Bonferroni convention. Superscript \# represents effect size $(d)$ and $95 \%$ confidence interval (in parenthesis) of $0.22(0.1 ; 0.4)$. 

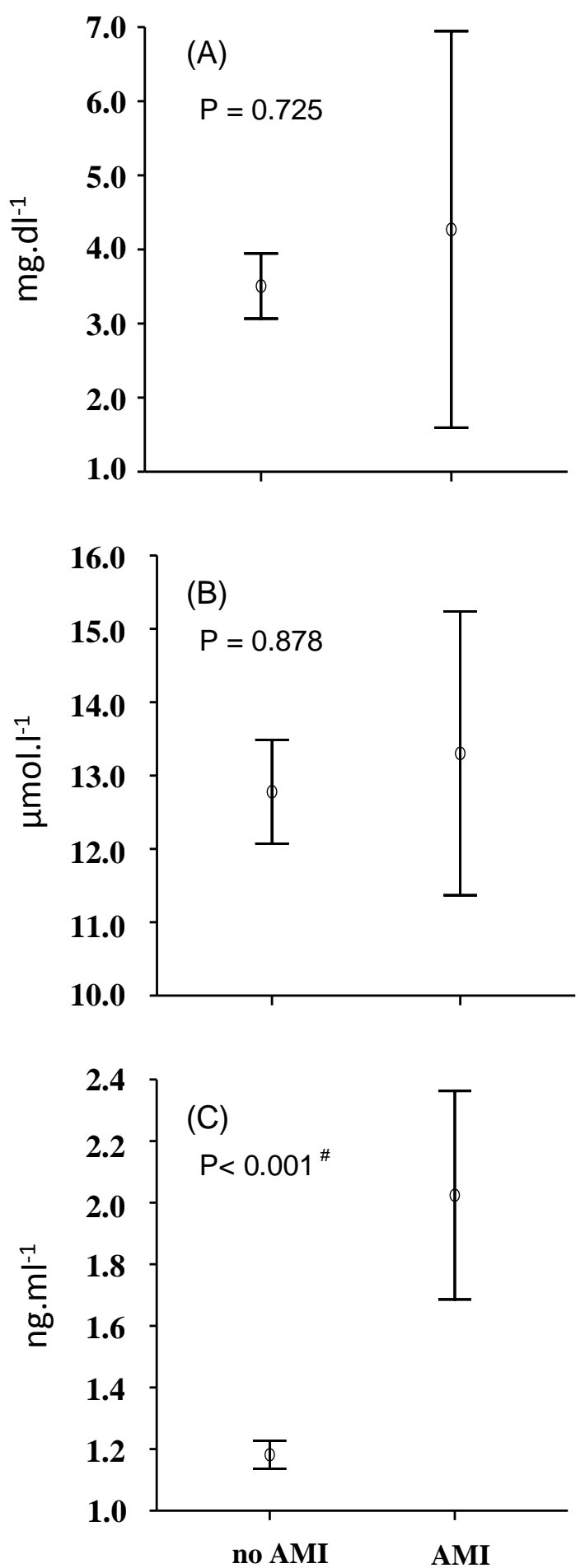

Figure 1. Comparison of raw circulating levels of C-reactive protein (A), homocysteine (B) and klotho (C) across individuals that exhibited prior acute myocardial infarction (AMI) or not. Significance was verified by the Student's $t$ test for independent samples. Vertical bars represent intervals of one standard error. Superscript \# represents effect size $(d)$ and 95\% confidence interval (in parenthesis) of 1.6 (0.9; 2.6). 